\title{
Predictive modelling of seabed habitats: case study of subtidal kelp forests on the coast of Brittany, France
}

\author{
Vona Méléder ${ }^{1,3,{ }^{*}}$, Jacques Populus ${ }^{1}$, Brigitte Guillaumont ${ }^{1}$, Thierry Perrot ${ }^{2}$ and Pascal Mouquet ${ }^{2}$ \\ 1 Ifremer, Dyneco/AG, BP 70, 29280 Plouzané, France \\ 2 CEVA, BP 3, L'Armor-Pleubian, 22610 Pleubian, France \\ ${ }^{3}$ Present address: Nantes Atlantique Université, Mer Molécule Santé/EA 21 60, BP 92208, 44322 Nantes cedex \\ 3, France \\ *: Corresponding author : Vona Méléder, email address : vona.meleder@univ-nantes.fr
}

\begin{abstract}
:
Predictive modelling to map subtidal communities is an alternative to "traditional" methods, such as direct sampling, remote sensing and acoustic survey, which are neither time- nor cost-effective for vast expanses. The principle of this modelling is the use of a combination of environmental key parameters to produce rules to understand species distribution and hence generate predictive maps. This study focuses on subtidal kelp forests (KF) on the coast of Brittany, France. The most significant key parameters to predict KF frequency are (1) the nature of the substrate, (2) depth, (3) water transparency, (4) water surface temperature and (5) hydrodynamics associated with the flexibility of algae in a flow. All these parameters are integrated in a spatial model, built using a Geographical Information System. This model results in a KF frequency map, where sites with optimum key parameters show a deeper limit of disappearance. After validation, the model is used in the context of Climate Change to estimate the effect of environmental variation on this depth limit of KF. Thus, the effects of both an increase in water temperature and a decrease in its transparency could lead to the complete disappearance of $\mathrm{KF}$.
\end{abstract}


39 Traditionally, marine ecologists have used the direct sampling method to characterise

40 shallow water and intertidal marine habitats. However, this method is neither time-

41 nor cost effective for expanses from a regional to a global scale. Remote sensing

42 tools, such as aerial photography, airborne and satellite imagery, are appropriate for 43 surveying and classifying marine habitats in the intertidal zone (Guillaumont et al. 44 1993; Bajjouk et al. 1996; Guillaumont et al. 1997; Méléder et al. 2003; Combe et al. 45 2005). However, these tools rapidly reach their limits for subtidal surveys because of the absorption of visible radiations by water. Both single-beam and sidescan acoustic methods are suitable to overcome this limitation and to achieve remote sensing of depth and benthic communities in subtidal waters (McRea et al. 1999; Piazzi et al. 2000; Brown et al. 2002; Freitas et al. 2003; Riegl et al. 2005; Freitas et al. 2006).

50 But as these techniques involve either profiles or narrow swaths, their efficiency of 51 coverage is quite limited and addressing areas from regional to global scale leads to dramatically increased costs. Acoustic methods also have limited discriminatory ability between macrophyte types and densities although recent works show their capability to coarse estimate macrophytic biomass (Riegl et al. 2005). So, for spatial assessment of seabed habitats, prediction using models seems to be the best approach. Depending of the objective of the survey and the availability of data to build models, assessment could include the occurrence, the biomass, the density and/or the diversity of habitats. Although these tools cannot replace direct detection or observation of benthic surfaces, they can provide a more global vision of some

60 seabed habitats that is compatible with ecosystem management. The development of 61 predictive models will contribute to better understanding of the factors and processes 62 which structure the distribution and composition of marine habitats and their 
63

64

65

66

associated biological communities at a coarser yet more integrated scale than that achieved using direct methods. Once developed and validated, these models are time- and cost-beneficial tools and enable the coverage of areas where no habitat information is available. Besides, they offer a way to apply scenarios to simulate effects of environmental changes on habitats distribution, particularly in the contemporary context of the Climate Change (IPCC 2001).

Some combinations of environmental parameters, such as the so-called the 'marine landscape', are assumed to control the distribution of species and habitat types (Roff and Taylor 2000). Basically, the key parameters used can be grouped under three themes (Stevens and Connolly 2004), i.e., those concerned with 1 / the morphology of the bottom and the nature of the substrate (depth, sediment type, sediment constituents), $2 /$ the nature of the water body overlying the substrate (temperature, $\mathrm{pH}$, salinity, turbidity, nutrients) and 3/ the dynamics of the local environment or water mass (exposure to waves, current velocity). Since the approach proposed by Roff \& Taylor in 2000 to predict the distribution of species and habitat types using 'marine landscapes', there have been a few examples of marine habitat classification in a spatial context based on physical factors (Zacharias et al. 1999; Kelly et al. 2001; Zacharias and Roff 2001; Brinkman et al. 2002; Stevens and Connolly 2004; Greve and Krause-Jensen 2005; De Oliveira et al. 2006). Applied to a marine context, these methodologies are expected to produce rules to understand species distribution according to environmental parameters and hence, predictive maps.

The aim of this study, part of a modelling work package of the MESH project (Mapping European Seabed Habitats), an Interreg IIIB North-West Europe funded initiative, is to propose a predictive model of kelp forest (hereafter called KF) 
87 frequency, i.e., the percentage of their presence along the coast of Brittany, France.

88 Indeed, seaweeds are an important component of coastal primary production. With a 89 primary production ranging from 400 to $1900 \mathrm{~g} \mathrm{C} \cdot \mathrm{m}^{-2} \cdot \mathrm{y}^{-1}$ (Sivertsen 1997), KF can be compared to the most productive terrestrial ecosystems (Hurd 2000). Characterised by densities of more than $\underline{3 \text { plants. } \mathrm{m}^{-2}}$ and made up of various seaweed species belonging to the Laminariales order, essentially Laminaria digitata and Laminaria hyperborean, KF are often the dominant producers in nearshore ecosystems, supplying higher trophic levels via herbivory or the detrital food chain (Hurd 2000 and references within). KF also provide an essential habitat and food for hundreds of marine invertebrates and fish species living in temperate nearshore waters

97 (Norderhaug et al. 2002 and references within). However, they also react to changes 98 in environmental changes and/or quality (Dayton et al. 1992; Ferrat et al. 2003). 99 Finally, KF are used in many maritime countries for industrial applications and as a fertiliser. This means that there is a steady demand for raw material from the 101 seaweed industry, adding economic importance to their ecological one.

102 In this current study, KF frequency is predicted as a function of the depth and the 103 chosen methodology for the prediction is the stepwise multiple regression process 104 with a backward selection of environmental variables: water transparency, 105 temperature and water motion. The software used to build and validate the model 106 and to display the resulting map is a Geographical Information System (GIS), ArcGIS 107 9.0. After validation, model is used in the context of Climate Change to estimate the 108 effect of environmental variation on KF distribution. 
113 Environmental variables

114 Nature of substrate - As KF are mainly found on rocky substrata, the prediction of 115 their occurrence was limited to this kind of substrate. Thus, maps of rock in shapefile 116 format were used as masks to force the model in the GIS software, namely digital 117 sediment maps (SHOM 1994-2005) with a resolution of 1:50,000 and where not 118 available, a coarser 1:500,000 map (Vaslet et al. 1979).

119 Bathymetry - The bathymetry map was a raster dataset from the French Channel 120 coast to the Gironde estuary, with a resolution of $150 \mathrm{~m}$. This raster was generated 121 using various types of digital and map depth data that were interpolated by kriging, a 122 geostatistical method. Bathymetry was expressed in metres with respect to the LAT 123 (lowest astronomical tide level). However, this depth did not correspond to the real 124 water column height, since LAT levels are rarely reached. Therefore, depth values were locally corrected by the annual mean tide level, leading to a new raster dataset of water column height to be used as an input for the predictive model. For the sake

127 of simplicity, this water height will be called "depth" in the paper.

128 Another bathymetric derivative was also calculated, the BPI (Bathymetric Position 129 Index, Lundblad et al. 2004). This index enabled the topography to be estimated 130 (crest / depression / flat or slope) by measuring where a given depth cell was located 131 with regard to the overall landscape. In the present case the mean depth of the 132 surrounding cells was computed using a 4 cell radius annulus. The cells in the 133 resulting raster dataset were assigned values within a range of positive and negative 134 numbers. A positive BPI indicated a cell on a crest, whereas a negative index was 135 found where a depression occurred. Flats areas or areas with a constant slope 136 produced index values near zero (Lundblad et al. 2004). 
137 Water transparency - In coastal waters, light is very often a key limiting factor for the

138 growth of photosynthetic organisms such as the laminarial algae constituting KF, and

139 the light attenuation coefficient in the euphotic layer is a major parameter used in

140 ecological modelling. Thus, the attenuation coefficient of the photosynthetically

141 available radiation (PAR domain [400 - $700 \mathrm{~nm}$ ), $\mathrm{K}_{\mathrm{PAR}}$ enabled the light attenuation

142 throughout the water column to be modelled. This coefficient, derived from the water

143 optically active components related to chlorophyll, suspended particulate matter and

144 dissolved organic matter could be used as a water turbidity proxy. Hence, a high

145 attenuation coefficient illustrates a turbid water column. In this study, $\mathrm{K}_{\mathrm{PAR}}$ was

146 derived from SeaWiFS (Sea Wide Field Sensor) satellite reflectance, combining

147 chlorophyll and suspended matter optical properties (Gohin et al. 2005). 52 weekly

148 mean images of $K_{P A R}$ were obtained from SeaWiFS data averaged over the 1998-

1492004 period, with a resolution of $1,100 \mathrm{~m}$.

150 From this $\mathrm{K}_{\mathrm{PAR}}$ the fraction of light reaching the bottom (Fr) was estimated for a given

151 depth $\mathrm{h}$ by:

$152 \operatorname{Fr}=\left(\exp ^{\mathrm{h} \times \mathrm{K}_{\text {PAR }}}\right) \times 100(\%)$

153 When this percentage is equal to $1 \%$, it defines the lower limit of the photic zone.

154 Below this threshold, the remaining energy is not efficient for photosynthesis.

155 Temperature - This factor was estimated by Sea Surface Temperature (SST, in ${ }^{\circ}$ )

156 derived from AVHRR (Advanced Very High Resolution Radiometer) data with a

157 resolution of $1,100 \mathrm{~m}$. SST maps were provided by the SAF (Satellite Application

158 Facility) "Ocean and Sea Ice" of EUMETSTAT/Meteo-France, Lannion (France) and

15952 weekly mean images were available from AVHRR reflectance averaged over the 160 last two decades. 
161 Water motion - This variable was expressed as the tidal current maximum velocity

162 (Vmax in $\mathrm{m}^{-1} \mathrm{~s}^{-1}$ ) resulting from simulations for a mean spring tide run by the

163 hydrodynamic model MARS 3D developed at Ifremer. The current resolution of this

164 model is $300 \mathrm{~m}$.

165

166 Biological variables: KF ground-truthing

167 Acoustic surveys of laminarial algae belonging to KF were carried out at 10 locations

168 along the Coast of Brittany in three periods: spring 2005 for the Aber Wrac'h (AW)

169 site, spring 2006 for the Groix (Gr), Molène (Mo), Méloine (Me) and Triagoz ( $\operatorname{Tr}$ ) sites

170 and spring 2007 for the Audierne (Au), Bréhat Island (Br), Glénan (Gl), Heaux (He)

171 and Moelan (Ml) sites (Figure 1). All sites were chosen for the presence of rocky

172 substrata and the accessibility to survey boat. Prospected zone for each site was

173 delimited using rock and bathymetry maps to identify flat rocky area located at a

174 bathymetry varying from 10 to $30 \mathrm{~m}$, where KF were more susceptible to be found.

175 On field, a small survey boat equipped with a $120 \mathrm{kHz}$ Simrad EK60 echo-sounder 176 was used. The narrow $7^{\circ}$ width beams were used for e mitting and receiving. The

177 acquisition parameters of the transducer, adjusted to the minimum pulse duration (64

$178 \mu \mathrm{s}$ ) and sampling interval (pulse frequency: $16 \mu \mathrm{s}$ ), made it possible to obtain the

179 maximum resolution on both vertical and horizontal axes. All recordings were

180 performed at a constant speed of about 5 knots corresponding to a distance between

181 each pulse (or ping) varying from 5 to $20 \mathrm{~cm}$. The total track length for each site was

182 about 20 kilometres. Acoustic transects were simultaneously georeferenced with a

183 GPS equipped with the EGNOS system giving position accuracy of better than three

184 metres. Both acoustic and position data were stored on a laptop PC. 
185 Data processing - Raw acoustic data were post-processed using MOVIES+ echo 186 integration software (Marchalot et al. 2003) which can be used to evaluate the backscattered energy in different depth layers defined by the user above or below the seafloor (Figure 2, line A). The first layer was defined at $0.2 \mathrm{~m}$ above the sea bottom to detected KF (Figure 2, line B) and the second from 1 to $1.5 \mathrm{~m}$ under the sea 190 bottom to evaluate the nature of the seafloor (not shown in Figure 2). The top limit of 191 the integrated layer was set at $2.2 \mathrm{~m}$ above the bottom (line C). On each ESU 192 (Elementary Sampling Unit, Figure 2), defined by a 20-ping width and a spatial 193 resolution varying from 1 to $4 \mathrm{~m}$ (depending on the speed of the boat), the software 194 gives four parameters for each layer: $\mathrm{Ni}$ (number of echo-integrated samples), $\mathrm{Nt}$ 195 (total number of samples), $s A$ (nautical area scattering coefficient in the layer in $196 \mathrm{~m}^{2} / \mathrm{mille}^{2}$ ) and $\mathrm{sV}$ (volume reverberation index of the layer in $\mathrm{dB}$ ). The additional 197 parameter BotErr (for Bottom Error), provided by the software when a large variation 198 is detected in the echo-integrated energy, may indicate that the bottom itself has 199 accidentally been integrated in the first bottom layer (i.e., the one nearest the sea 200 bed, see Figure 2, line A). Once the raw acoustic data have been processed using 201 MOVIES+, a specific algorithm implemented with the Excel software based on 202 thresholds and ratio values of $\mathrm{Ni}, \mathrm{Nt}, \mathrm{sA}$ and BotErr automatically classifies KF 203 presence or absence (binary) and the type of substrate (rock or sand). The algorithm 204 was validated using direct observations by scuba-divers on the AW site during spring 2052005 and in the Gr, Mo, Me and Tr sites during the spring 2006.

206 Thus, the resulting data for each ESU were the coordinates of the point (lat, long), 207 the KF presence or absence, the nature of the substratum, and the depth (in metres). 208 The latter, initially measured with reference to LAT, was corrected by adding the 209 annual mean tide level. 
210 The echo-integration results were used to build KF distribution laws, expressed for

211 each site in "percentage of presence" or "frequency" (\%) as a function of depth $(\mathrm{m})$.

212 KF frequency, $F_{[H]}$, was obtained for depths between 10 and 30 m by:

213

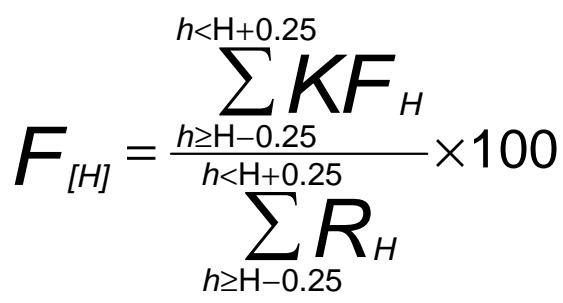

214 where $\mathrm{H}$ was the class of depth split into $0.5 \mathrm{~m}$ intervals and $h$ the depth from echo-

215 integration falling into this class, $K F_{H}$ the total amount of ESU corresponding to KF for

216 the given class $\mathrm{H}$ and $R_{H}$ the total amount of ESU corresponding to rock substratum

217 for the same class $\mathrm{H}$.

218 These frequency laws were fitted using piecewise regressions (Toms and

219 Lesperance 2003) from SigmaPlot 10.0 software following the process:

220

$$
\mathrm{h}_{1}=\min (\mathrm{h})
$$

221

$$
\mathrm{h}_{3}=\max (\mathrm{h})
$$

222

223

224

$$
\text { segment1 }(h)=\left(y_{1} \times\left(H_{1}-h\right)+y_{2} \times\left(h-H_{1}\right)\right) /\left(H_{1}-h_{1}\right)
$$

227 The fit was sought for the two breakpoints $\mathrm{H}_{1}$ and $\mathrm{H}_{2}$ and Slope $\mathrm{S}_{2}$, the slope between

228 them (Figure 3). $\mathrm{H}_{1}$ and $\mathrm{H}_{2}$ were the depths corresponding respectively to the

229 beginning of the frequency decrease and to the disappearance of KF, (which is also

230 the upper limit of KF characterised by a density of less than 3 plants. $\mathrm{m}^{-2}$ ). These

231 three parameters were taken as the biological variables to be predicted using 
232 environmental ones. Each fit was expressed with its confidence and prediction 233 intervals at $95 \%$ (Figure 3).

Model building

236 The cell values of the environmental variable raster dataset (BPI, $\mathrm{K}_{\mathrm{PAR}}$, SST and

237 Vmax) intersected by acoustically surveyed transects were extracted and averaged 238 on a site basis. The values from five sites (AW, Mo, Me, Tr and Gr) called "training 239 sites" were used to build the predictive model of KF frequency, whereas the values 240 from the other five ( $\mathrm{Au}, \mathrm{Br}, \mathrm{Gl}, \mathrm{He}$ and $\mathrm{Ml}$ called "validation sites") were used to 241 validate it.

242 The methodology chosen for the prediction was the stepwise multiple regression with 243 a backward selection of variables. Associations of the BPI and/or $\mathrm{K}_{\mathrm{PAR}}$ and/or SST 244 and/or Vmax were used to predict $\mathrm{H}_{1}, \mathrm{H}_{2}$ and Slope ${ }_{2}$, and then to estimate KF 245 frequency for depths from $\mathrm{H}_{1}$ to $\mathrm{H}_{2}$ :

$$
\mathrm{H}_{1}=\mathrm{aBPI}+\mathrm{bSST}+\mathrm{cK}_{\mathrm{PAR}}+\mathrm{dVmax}{ }^{\beta}
$$

$$
\mathrm{H}_{2}=\mathrm{a}^{\prime} \mathrm{BPI}+\mathrm{b}^{\prime} S S T+\mathrm{c}^{\prime} \mathrm{K}_{\mathrm{PAR}}+\mathrm{d}^{\prime} \mathrm{Vmax}^{\beta}
$$

$$
\text { Slope }_{2}=\mathrm{a} \text { "BPI }+ \text { b"SST }+ \text { c"K PAR }+ \text { d"Vmax }{ }^{\beta}
$$

$$
\text { for } \mathrm{H}_{1}<\mathrm{h}<\mathrm{H}_{2}
$$

251 expressed the flexibility of algae in a flow, typically around 1.5 (Denny and Gaylord

252 2002). 2 and 1.5 were tested as values for $\beta$.

253

254 The prediction of KF frequency for a depth less than $\mathrm{H}_{1}$ is performed using the same 255 process: 
for $\mathrm{h}<\mathrm{H}_{1}$

258 where $w$ to $z$ are the regression coefficients (might be $=0$ ) and $\beta=1.5$ or 2 .

260 Stepwise regressions were run using the statistical software R.2.5.1. However, the

261 use in regression process of the 52 weekly values extracted from $\mathrm{K}_{\mathrm{PAR}}$ and SST

262 images was not relevant. For this reason, water transparency and surface

263 temperature information were synthesised using both the annual average (namely

$264 \mathrm{~K}_{\mathrm{PAR}}$ year and SSTyear) and the average during the growth period from week 14 to

265 week 25 (namely K

266 during the year (K $\mathrm{K}_{\mathrm{PAR}} \mathrm{min}$, SSTmin, $\mathrm{K}_{\mathrm{PAR}} \max$ and SSTmax) were also integrated in

267 the stepwise regression process. Then environmental variables with a non-significant

268 partial F ( $p \leq 0.1)$ were removed step by step. However, varying significant multiple

269 or simple regressions were obtained to predict the same biological variables. All

270 these regressions were used to build varying predictive models, and the one showing

271 the smallest residual differences between predictions and observations was kept to

272 produce the final predictive map. This map was then built by automating the model

273 work flow with the 'ModelBuilder' interface in the ArcGIS 9.0 geoprocessing toolbox.

274 Moreover, this interface allowed to create the environmental settings for the model,

275 which controlled geoprocessing output parameters. Raster analysis settings were

276 used to give the output cell size, defining working scale, the finest resolution among

277 the various data sources, $150 \mathrm{~m}$, and to apply the rock mask.

278

279 Validation and simulations

$280 \mathrm{KF}$ frequency obtained by echo-sounding from the 5 sites: $\mathrm{Au}, \mathrm{Br}, \mathrm{Gl}, \mathrm{He}$ and Mo

281 (Figure 1) was compared to the prediction at the same location to validate the model. 
282 It was then used in the context of Climate Change to estimate the effect of

283 environmental variation on the depth of KF disappearance, $\mathrm{H}_{2}$. Indeed, since 1976,

284 temperature of the ocean increase by $0.075 \mathrm{C} /$ decad e, i.e. an increase of around

$2850.2^{\circ} \mathrm{C}$ during the 30 past years (IPCC 2001). For th e northern hemisphere, where

286 this study sites are located, the increase of temperature is higher with $0.4 \mathrm{C} / \mathrm{decade}^{\mathrm{C}}$

287 i.e. around $1^{\circ} \mathrm{C}$ since 1976 (IPCC 2001). Using the validated model, two scenarii

288 were tested for temperature increase in accordance to IPCC (2001) results: the

289 global $\left(0.2^{\circ}\right)$ and the northern increase $\left(1^{\circ} \mathrm{C}\right)$. A $n$ intermediate stage (an increase

290 of $0.5^{\circ}$ ) was used in a third simulation. In the s ame way, three scenarii to estimate

291 effect of an increase of water transparency on KF distribution were tested. Indeed,

292 extreme episodic events such as storms, extreme rain events and flooding must a

293 consequence of the Climate Change (IPCC 2001). These result in strong

294 hydrodynamics and super river discharges leading to decrease of water transparency

295 (de Jonge and de Jong 2002; Cardoso et al. 2008). However, no information about

296 the evolution of the water transparency proxy use in this study, the $K_{P A R}$, is available.

297 Steps to simulate increase of K PAR values for the three scenarii were chosen to test

298 K KAR values included in the range of values used to build the model: $0.01,0.02$ and

$299 \underline{0.05}$.

300

301 RESULTS

302 Environmental parameters

$303 \mathrm{Gr}$, He and $\mathrm{Br}$ sites were the more turbid locations throughout the year and during

304 the growth period with the greatest $\mathrm{K}_{\mathrm{PAR}} \mathrm{year}$ and $\mathrm{K}_{\mathrm{PAR}}$ growth values (Table 1). For

305 these three sites, the minimum values ( $\left.\mathrm{K}_{\mathrm{PAR}} \mathrm{min}\right)$ never went below 0.18 , whereas

306 maximum values (KAR $\mathrm{Kax}$ ) reached 0.456 at the $\mathrm{Gr}$ site during week 2 (Table 1, 
307 Figure 4). On the other hand, the western sites Mo and Au were the clearest

308 locations with lowest $\mathrm{K}_{\mathrm{PAR}}$ values (Table 1).

309 Along with this spatial variability along the coast of Brittany, water transparency also

310 varied over time. Peaks of $K_{P A R}$, often exceeding 0.25 , were detected during the first

311 seven weeks and the last twelve weeks (Figure 4). These periods corresponded

312 respectively to winter and autumn, periods of bad weather with rain and storms often

313 leading to increased amounts of mineral material from either bottom scouring or river

314 discharge. The maximum $\mathrm{K}_{\mathrm{PAR}}$ values reported in Table 1 were recorded during

315 these weeks. Conversely, the minimum $\mathrm{K}_{\mathrm{PAR}}$ values ( $\mathrm{K}_{\mathrm{PAR}} \mathrm{min}$, Table 1$)$ were

316 observed during spring/summer between weeks 10 and 40 . This period

317 corresponded to calm weather, although some turbulent and stochastic events

318 appeared and generated turbidity peaks lasting from one to three weeks but never

319 resulting in a $\mathrm{K}_{\mathrm{PAR}}$ above 0.25 (Figure 4). These peaks were essentially observed at

$320 \mathrm{AW}, \mathrm{Gr}, \mathrm{Br}$ and He sites, whereas the other sites were more stable in terms of water

321 transparency (Figure 4).

322

323 Surface temperature showed spatial and temporal variability very similar to that of

324 water transparency. The warmest sites during the year were those located in the

325 south: $\mathrm{Gr}, \mathrm{Gl}$ and $\mathrm{Ml}$ with respectively $13.6,13.7$ and $13.5^{\circ} \mathrm{C}$ (Table 1 ), which also

326 exhibited growth period temperature values in excess of $12.5^{\circ} \mathrm{C}$. The coldest site

327 was $\mathrm{AW}$ with more than $1^{\circ} \mathrm{C}$ below the annual means of the southern sites. The

328 other sites showed equivalent annual SST values, around $13^{\circ} \mathrm{C}$ (Table 1).

329 The temporal variability was classic, with high temperatures in summer, and low

330 temperatures in winter (Figure 5). However the Gr site, although it was one of the

331 warmest, showed the minimum temperature value $\left(8.7^{\circ} \mathrm{C}\right)$, due to a well-known 
332 tongue of cold water occurring near the coast. The other southern sites showed the

333 highest minimum and maximum temperature values (Table 1, Figure 5).

334

335 Exposure, measured by the maximum tidal current velocity Vmax, showed a

336 north/south gradient whose maximum velocity was lower than $0.3 \mathrm{~m} . \mathrm{s}^{-1}$ for southern

337 sites, although it reached $1 \mathrm{~m} \cdot \mathrm{s}^{-1}$ for the more turbulent northern sites (Table 1).

338

339 Surveying KF with echo-sounding

340 The parameters described in the Materials and Methods section were calculated for

341 the echo signals collected over the study areas and the binary classification of KF

342 (presence/absence) was performed for each site. For illustrate results, only part of

343 the echogram for the Gl site and the corresponding classification are shown in Figure

344 6. The acoustic signal from $\mathrm{KF}$ is about 1 metre high with quite low backscatter

345 energy (light grey) above the seafloor (dark grey). There was good correlation

346 between underwater KF boundaries as indicated by the echogram and the

347 classification (dark hatches). Sometimes, accidental bottom integration causes

348 classification of the ESU in BottErr (light hatches). This phenomenon is generally

349 seen on steeper rocky substrates and is amplified by bad weather conditions.

350

351 KF frequency law

352 Overall, the sites showed the same significant distribution profile along the depth

353 (Figure 3, Table 2), except for those of $\mathrm{Au}, \mathrm{He}$ and $\mathrm{Ml}$, for which some fit parameters

354 are not significant (Table 2). The profile was divided in two parts. The first, before the 355 inflexion point $\mathrm{H}_{1}$, corresponded to the variability of frequency around a mean (Figure 356 3). The slope of this first segment was not significant, and thus, was not predicted by 
357 the model. Indeed, the frequency for depths less than $\mathrm{H}_{1}$ up to the upper KF limit 358 were directly predicted using environmental parameters (eq. 10). The second part of 359 distribution law corresponded to a drop in the frequency along Slope $\mathrm{e}_{2}$, between $\mathrm{H}_{1}$, 360 and $\mathrm{H}_{2}$, the depth at which KF disappeared (eq. 4 to 6). Fits are good, with high 361 adjusted $\mathrm{R}^{2}$ and a probability of less than 0.01 (Table 2). $\mathrm{H}_{1}$ varies from $13.2 \mathrm{~m}$ for 362 the most turbid and coldest site $\mathrm{Br}$, to $20.6 \mathrm{~m}$ for the clearest and warmest one, Mo 363 (Tables 1 and 2). Likewise, Slope ${ }_{2}$ is higher in turbid (low transparency) and cold 364 sites, such as $\mathrm{Au}$ and $\mathrm{Br}$, than in less turbid and warmer sites such as $\mathrm{Me}$ and $\mathrm{AW}$ 365 (Tables 1 and 2). Similarly to $\mathrm{H}_{1}$ and Slope ${ }_{2}, \mathrm{H}_{2}$ varies with the water transparency 366 and surface temperature from $19.3 \mathrm{~m}$ to $27.8 \mathrm{~m}$. However, the relationship between

$367 \mathrm{H}_{2}$ and water transparency and/or surface temperature is not as clear as that 368 explaining $\mathrm{H}_{1}$ and Slope ${ }_{2}$, suggesting the effect of another environmental parameter 369 to explain explaining KF disappearance, which could be bed stress.

370 Once $\mathrm{H}_{2}$ was known, the Fr fraction (eq. 1) for each site was calculated using the 371 four water transparency parameters $K_{\text {PAR }}$ year, $K_{\text {PARgowth, }} \mathrm{K}_{\mathrm{PAR}}$ min and $\mathrm{K}_{\mathrm{PAR}} \mathrm{max}$ 372 (Table 3). Only $\mathrm{K}_{\mathrm{PAR}}$ growth and $\mathrm{K}_{\mathrm{PAR}}$ min values allowed Fr higher than the 1\% 373 threshold permitting photosynthesis activity. The use of $\mathrm{K}_{\mathrm{PAR}} \mathrm{year}$ and $\mathrm{K}_{\mathrm{PAR}} \max$ 374 generated Fr values below the 1\% level which were inconsistent with algal presence 375 such as KF or parks. Thus, only $\mathrm{K}_{\mathrm{PAR}}$ growth and $\mathrm{K}_{\mathrm{PAR}}$ min seemed to be relevant and 376 biologically interpretable abiotic factors to predict $\mathrm{H}_{2}$ and hence KF frequency.

378 Predictive modelling

379 Stepwise regression processes provided four significant models to predict KF 380 frequency from the five training sites AW, Mo, Me, Tr and Gr, for a depth ranging 381 from $\mathrm{H}_{1}$ to $\mathrm{H}_{2}$ following the equations (6) to (9). The first model predicted biological 
382 variables $\left(\mathrm{H}_{1}, \mathrm{H}_{2}\right.$ and $\left.\mathrm{Slope}_{2}\right)$ using SSTmin only (eqs. 11 to 13 ) and the second one 383 used K KAR min only (eqs. 14 to 16). The last two significant models were similar to the 384 first two, but with a better predictive $\mathrm{H}_{2}$ using Vmax ${ }^{1.5}$ in addition to SSTmin or $385 \mathrm{~K}_{\text {PAR min }}$ alone (eqs. 17 and 18). The adjusted $\mathrm{R}^{2}$ increased from 0.80 to 0.98 when $386 \mathrm{Vmax}{ }^{1.5}$ was associated with SSTmin, and from 0.76 to 0.97 when $\operatorname{Vmax}^{1.5}$ was 387 associated with $\mathrm{K}_{\mathrm{PAR}} \mathrm{min}$ :

388

389

pred_mod1,

390

$\mathrm{H}_{1}=-29.81+5.31 \times \mathrm{SSTmin}$

$R^{2}=0.88, p \leq 0.05$

391

$\mathrm{H}_{2}=-30.32+5.86 \times$ SSTmin

$R^{2}=0.80, p \leq 0.05$

392

Slope $_{2}=28.53-4.23 \times$ SSTmin

$R^{2}=0.79, p \leq 0.05$

393 pred_mod2,

394

$$
\mathrm{H}_{1}=40.5-121.19 \times \mathrm{K}_{\mathrm{PAR}} \mathrm{min}
$$$$
\mathrm{R}^{2}=0.87, \mathrm{p} \leq 0.05
$$

395

$$
\mathrm{H}_{2}=40.75-130.97 \times \mathrm{K}_{\mathrm{PAR}} \min
$$$$
R^{2}=0.76, p \leq 0.05(15)
$$

396

Slope $_{2}=-25.37+84.72 \times \mathrm{K}_{\mathrm{PAR}} \mathrm{min}$

$R^{2}=0.60, p=0.12$

397

pred_mod3,

398

$$
H_{1}=\text { eq. (14) }
$$

399

$$
\mathrm{H}_{2}=43.53-121.12 \times \mathrm{K}_{\mathrm{PAR}} \min +2.26 \times \mathrm{Vmax}^{1.5} \mathrm{R}^{2}=0.97, \mathrm{p} \leq 0.05(17)
$$

400

Slope $_{2}=$ eq. (16)

401

pred_mod4,

402

$$
\mathrm{H}_{1}=\text { eq. (11) }
$$

403

$$
\mathrm{H}_{2}=-26.86+5.33 \times \mathrm{SST} \min +2.07 \times \operatorname{Vmax}^{1.5} \quad \mathrm{R}^{2}=0.98, \mathrm{p} \leq 0.05
$$


405 For each model, the KF frequency was predicted following equation (9). Thus, the 406 most efficient model was that reducing residuals between observation and prediction 407 (Figure 7). These residuals showed that models including temperature or water 408 transparency only (respectively pred_mod1 and pred_mod2) were not able to predict 409 KF frequency correctly (Figure 7a and 7b). Indeed, SSTmin on its own (pred_mod1) 410 predicted KF frequency well only for the Gr and Me sites, whereas this model 411 overestimated percentages for the sites AW and Mo and underestimated them for $\mathrm{Tr}$ 412 (Figure 7a). On the contrary, $\mathrm{K}_{\mathrm{PAR}} \min$ (pred_mod2, Figure 7b) enabled good 413 prediction for the latter site as well as for Me, while it overestimated observations for 414 Mo and underestimated those on AW. The use of water motion, estimating bed 415 stress using $\operatorname{Vmax}^{1.5}$, was more efficient (Figure 7c and 7d) particularly when it was 416 associated with water transparency (Figure 7c). Only the observed frequencies from 417 the Gr site were not well predicted using the model 'pred_mod3' but this was due to 418 incomplete coverage by SeaWiFS data for this site. Therefore, the model using 419 SSTmin and $\operatorname{Vmax}^{1.5}$ (Figure $7 \mathrm{~d}$ ) was run for part of this site and other locations 420 where water transparency data were not available.

421 Models were able thus to predict a decrease in depths $\mathrm{H}_{1}$ and $\mathrm{H}_{2}$ with water clarity, 422 while an increase in temperature indicated deeper breakpoints. When clearness or 423 surface temperature of water was constant a drop in the depth limit $\mathrm{H}_{2}$ occurred in a 424 direct ratio with a power of 1.5 for the velocity. Finally, the model providing the best 425 prediction of KF frequency for depths between $\mathrm{H}_{1}$ to $\mathrm{H}_{2}$ was pred_mod3, using water 426 transparency and bed stress, or pred_mod4 when water transparency data were not 427 available. 
429 However, the only significant model to predict KF frequency for a depth less than $\mathrm{H}_{1}$,

430 following equation (10) was that using topography (BPI) alone:

433 This regression indicates that KF were observed preferentially in depressions rather

434 than on crests. But, the attempted validation of this model concluded that using BPI

435 as a physical parameter can correctly predict KF frequency values around $50 \%$

436 (Figure 8). Under or above this frequency, BPI alone did not explain occurrences of $437 \mathrm{KF}$ in well-lit water.

438 The prediction was stopped at the $+1 \mathrm{~m}$ depth contour, known to be the higher limit of 439 KF presence. It was not possible to predict this limit at the study scale, as was done 440 by De Oliveira (2006) who used the percentage of immersion over the year, derived 441 from the tidal flooding frequency at a given elevation. This limit occurred for KF 442 between immersion periods ranging from 92 to $97 \%$ whereas maximum KF 443 coverage occurred at $100 \%$ immersion. The depth contours corresponding to $95 \%$ 444 and $100 \%$ immersion were too closes (only a few tens of metres), so they were 445 included in the same pixels of the bathymetry dataset used in our model. Therefore, 446 estimating and mapping the decrease in KF frequency between these two contours 447 at our working scale $(150 \mathrm{~m})$ was not possible.

448 Model validation

449 Validation sites $\mathrm{Au}, \mathrm{Br}, \mathrm{Gl}, \mathrm{He}$ and $\mathrm{Ml}$ (Figure 1) were used to validate the selected 450 model providing the better prediction, by looking at the residuals between the KF 451 frequency obtained by echo-sounding and predicted KF (Figure 9a). The prediction of 
$452 \mathrm{KF}$ frequency between $\mathrm{H}_{1}$ and $\mathrm{H}_{2}$ is satisfactory for $\mathrm{Au}$ and $\mathrm{Gl}$ sites but not as good

453 for $\mathrm{He}, \mathrm{Br}$ and $\mathrm{Ml}$ sites, for which some KF frequency predictions overestimated the 454 observations (Figure 9a).

455 For depths of less than $\mathrm{H}_{1}$, the model using BPI alone is not too effective (Figure 9b).

456 Observed frequencies varied from 10 to $64 \%$ for all the sites, whereas predictions 457 varied from 40 to $55 \%$. This indicates a limitation of the predictive model using only

458 BPI for depths less than $\mathrm{H}_{1}$.

459 In spite of these limits, the model provided good prediction of the boundary of KF

460 disappearance $\mathrm{H}_{2}$, on validation sites as well as on training sites (Table 4).

462 Predictive map

463 A predictive map is proposed to visualise areas where KF may occur as driven by 464 environmental parameters (Figure 10). Three examples were taken to illustrate this 465 map, AW, Br and Gl sites, respectively shown by black, red and blue boxes (Figure

466 10). $\underline{A W}$ is one of the sites showing highest hydrodynamism with great $V_{\max }$ and $K_{P A R}$

467 values, whereas $\mathrm{Gl}$ is one of the less agitated sites and $\mathrm{Br}$ shows an intermediate

468 stage.

469 KF disappear at greater depth when the water column is clear and not too cold. This

470 is the case for the site AW site (black box, Figure 10). On this site, KF regularly

471 reaches the $30 \mathrm{~m}$ depth contour. For more turbid and colder sites such as $\mathrm{Br}$, $\mathrm{KF}$ only

472 reaches the $20 \mathrm{~m}$ contour (red box, Figure 10). Exposure is also responsible for the 473 decrease in the KF depth limit. For example, although the GI site is clearer than AW,

$474 \mathrm{KF}$ there do not reach the $30 \mathrm{~m}$ contour, or only very locally (blue box, Figure 10).

475 This is explained by the lower maximum velocity at Gl than at AW (Table 1). 
477 Simulation

478 In the context of Climate Change, the model was used to predict the potential

479 variation in the KF disappearance depth, $\mathrm{H}_{2}$, with respect to various scenarios.

480 Simulations were based on an increase in $\mathrm{K}_{\mathrm{PAR}} \min$ of $0.01,0.02$ and 0.05 , except for

481 locations where no turbidity data were available. For the latter, SSTmin was used

482 with an increase of $0.2,0.5$ and $1^{\circ} \mathrm{C}$. The results illustrated the antagonism of these

483 two environmental parameters: an increase in water transparency induced an upward

484 shift of the KF boundary while temperature was responsible for a downward one

485 (Table 4). On sites AW, Me, Mo, Tr, Br, Gl and He (where $\mathrm{K}_{\mathrm{PAR}}$ min was used), $\mathrm{H}_{2}$

486 decreases of $1.2 \mathrm{~m}, 1.3 \mathrm{~m}$ and $3.6 \mathrm{~m}$ were obtained with $\mathrm{K}_{\mathrm{PAR}}$ min respectively

487 increasing by $0.01,0.02$ and 0.05 (Table 4). On the other hand, on sites for which

488 SSTmin was used ( $\mathrm{Gr}, \mathrm{Au}$ and $\mathrm{MI}), \mathrm{H}_{2}$ rose by $1,2.5$ and $5.5 \mathrm{~m}$ when SST

489 respectively increased by $0.2,0.5$ and $1^{\circ} \mathrm{C}$ (Table 4$)$.

490

491 DISCUSSION

492 Environmental effect - Antagonism between water transparency and water

493 temperature.

494 Water transparency and water temperature are the two main environmental variables

495 structuring KF frequency and distribution over the coast of Brittany. The results of this

496 study conclude that the annual minimum value of the light attenuation coefficient by

497 the water column is the most significant and relevant water transparency proxy for KF

498 prediction. This minimum value is measured during spring/summer, corresponding to

499 calm weather and thus to high water transparency because of limited sediment

500 scouring from the bottom and river discharges. It is also during this period that

501 maximum photosynthesis activity occurs, and the literature bears out that light 
502 attenuation by the water column is a key parameter in the structuring of macroalgae 503 communities, essentially during spring/summer (Belsher 1986; Markager and Sand504 Jensen 1992) because of this maximum photosynthesis activity. This period of the 505 year is favourable to KF growth all the more so nutrients are not limiting factors in 506 Brittany costal water (Ménesguen et al. 1997). This also explains why the value of 507 the light attenuation coefficient measured during the few weeks defining the growth 508 period is another relevant water transparency proxy for KF prediction. This is 509 supported by calculating the percentage of incident light lightening the limit of KF 510 disappearance. According to Markager and Send-Jensen (1992) and references 511 within showing the percentage of incidental light ranging from 0.7 to $1.9 \%$ reaching

512 the depth limit for Laminaria hyperborea, both minimum and growth values of $\mathrm{K}_{\mathrm{PAR}}$

513 are responsible for a percentage which is often higher than the $1 \%$ threshold 514 permitting photosynthesis. Then, below the KF depth limit, the remaining light energy 515 could be used by other photoautotrophic communities or organisms. KF are replaced 516 by less dense communities, such as laminarial parks characterised by a density of 517 less than 3 plants. $\mathrm{m}^{-2}$, and shade-loving species belonging to the Rhodophyceae 518 class like Solieria chordalis.

520 Using water transparency to predict the KF depth limit is also an interesting approach 521 in the context of Climate Change. Climate changes, including higher temperatures, 522 precipitation and wind speeds as well as storm events, may increase the risk of 523 abrupt and non-linear changes in many ecosystems, which would affect their 524 composition, function, biodiversity and productivity (IPCC 2001). Episodic events 525 such as storms, extreme rain events and flooding resulting in strong hydrodynamics 526 and super river discharges can lead to increased amounts of suspended mineral 
527 matter in the water column and on the bottom substrate (de Jonge and de Jong

528 2002; Cardoso et al. 2008). This turbidity increase is reinforced by anthropogenic

529 activities responsible for multiple stressors including pollutants, excess nutrients,

530 altered habitats and hydrological regimes as well as floods and droughts (Cardoso et

531 al. 2008). The response of KF to this drop in water transparency is bound to be an

532 upward shift of their lower limit.

533 Nevertheless, the KF depth limit shift due to natural or anthropogenic turbidity

534 increases could be counterbalanced by a rise in water temperature. Indeed, this

535 study concludes that $\mathrm{KF}$ take advantage of temperature increases, with communities

536 spreading towards deeper levels. The use of water temperature for prediction is more

537 relevant when values are measured outside of the summer period. During these

538 warm months, water column stratification can occur and therefore surface

539 temperature is not a good proxy for bottom temperature. The rest of the year, when

540 the water column is fairly homogenous and the bottom water is slightly cooler than at

541 the surface, surface temperature is a good proxy for the entire column. Next, one of

542 the structuring factors of Brittany KF communities is a minimum value of surface

543 temperature measured during winter, varying from 8.3 to $9.6^{\circ} \mathrm{C}$. These low

544 temperatures are without consequences for Laminaria digitata, the major species

545 providing high KF levels (approximately from the LAT down to a depth of $5 \mathrm{~m}$ ), as

546 their broad ecological optimum varies from 3 to $15^{\circ} \mathrm{C}$ (Belsher 1986). On the other

547 hand, L. hyperborea, the major species making up the lower-lying part of KF

548 (approximately from LAT to the depth limit) is more sensitive to cold temperature. Its

549 optimum is narrower than that of $L$. digitata, varying from 10 to $17 \mathrm{C}$ and young

550 sporophyte growth is altered at temperatures less than $10^{\circ} \mathrm{C}$ (Belsher 1986). This

551 explains why a rise in colder temperatures favours the spreading of these 
552 communities towards deeper levels. Using temperature measured during the cold

553 period for predictions is also an interesting approach in the case of Climate Change,

554 because water warming is mainly observed during this period (Koutsikopoulos et al.

555 1998). Nevertheless, although an increase in the coldest temperatures, as a

556 consequence of Climate Change, seems to favour a downward KF shift, this

557 phenomenon could be moderated or even reversed by the decrease in water

558 transparency during calm periods. These two parameters have an antagonistic effect

559 on KF structure.

560 Moreover, although the current model was not able to predict an effect on KF upper

561 limits, the temperature increase observed over the past decades (IPCC 2001) could

562 have an harmful effect on them. Indeed, L. digitata which occupies the upper part of

$563 \mathrm{KF}$, shows an optimum until $15^{\circ} \mathrm{C}$, and a lethal tempe rature value around $23-24{ }^{\circ} \mathrm{C}$

564 (Belsher 1986). The latter values have not been observed along the coast of Brittany

565 using the AVHRR scale, but, if surface temperatures kept increasing (as could be the

566 case locally), lethal values would soon be reached. This warming effect would lead to

567 KF reaching deeper and cooler water.

568 Then, in the worse Climate Change scenario, showing a rapid, high rise in

569 temperature with an increase in the number and intensity of extreme events (IPCC,

570 2001), the consequences will be an upward shift of the depth limit and a downward

571 one of the upper KF boundary, leading to a reduction in their width. If worse comes to

572 worst, the effects of both an increase in water temperature and a decrease in

573 transparency could lead to the complete disappearance of KF. This dramatic

574 consequence would lower or eliminate the habitat surface area and alter the

575 diversity, abundance and functioning of the associated biological communities. This

576 depletion of the ecosystem will also have economic consequences because of the 
577 decrease of this resource already threatened by over-cropping (MEDD 2005). All

578 these consequences will be irremediable if no global resolution like that

579 recommended by the Intergovernmental Panel on Climate Change (IPCC,

580 http://www.ipcc.ch) is adopted in the next few years.

582 Environment effect - Bed stress issue

583 Although the main studies assessing macro-algae with regard to exposure involve 584 wave swell effects and the intertidal area (Denny 1995; Hurd 2000; Denny and 585 Gaylord 2002; Buck and Buchholz 2005; Boller and Carrington 2006), this study 586 considered exposure due to tidal currents. Numerous authors have shown the effect

587 of orbital wave velocity, responsible for a drag force tending to push an object 588 downstream, which depends on the water density and velocity exponent of drag, $\beta$ 589 (Denny 1995). This exponent is derived from Vogel's $E$ (Vogel 1994), and measures 590 the relationship between velocity and drag. It determines how force increases with an 591 increase in water velocity. For bluff objects subjected to drag, $\beta$ is approximately 2 592 (Denny 1995; Denny and Gaylord 2002) and numerous authors take this value for all 593 objects, whether flexible or not (Buck and Buchholz 2005; Boller and Carrington 594 2006; Pope et al. 2006). However, Vogel (1994) and Denny (1995) suggest that an 595 exponent value lesser than 2 be used for streamlined or flexible objects. Indeed, in a 596 unidirectional flow, algal fronds bend in response to the force applied, and the plant 597 reorients and rearranges itself passively in a way resulting in overall streamlining 598 (Denny 1995 and references within). Consequently, the $\beta$ for exposed algae in flow is 599 universally less than 2 and typically around 1.5 (Denny 1995), with the velocity600 dependant character of shape being incorporated in this exponent. In this study, 601 because of the lack of swell data for the entire survey area at an appropriate scale, 
602 the effect of tidal current velocity was tested as a proxy for global water motion. The 603 results confirm Denny's suggestion: the value 1.5 for velocity exponent of drag is 604 more significant than the value 2, although water velocity does not have the same 605 source (swell vs. tide). The effect of a velocity increase is positive for KF: for sites 606 with the same water transparency conditions, a velocity greater than $0.8 \mathrm{~m} . \mathrm{s}^{-1}$

607 induces a downward shift of KF depth limit. This could be explained by a regular 608 cleaning effect of thalli in wild sites, making them more receptive to 609 photosynthetically available radiation than in sheltered sites where thalli are often 610 covered with a thin layer of particles. On the other hand, and although this has not 611 been observed on the scale and the sites of this study, too high a velocity is not

612 beneficial for KF, which could be dislodged or destroyed, as shown in situ or 613 experimentally for a number of macroalgae species (Gaylord et al. 2003; Buck and 614 Buchholz 2005; Boller and Carrington 2006). Indeed, the shear stress imposed on a 615 structure by water velocity of $2 \mathrm{~m} . \mathrm{s}^{-1}$ is roughly equivalent to that exerted by wind of 616130 mils. $^{-1}$ (Denny and Gaylord 2002).

617 Another proxy for exposure is the topography. This environmental variable is the only 618 one explaining KF structures when water temperature and transparency are not 619 limiting factors, that is to say in shallow depths. KF are observed more often, on a 620 working scale, in depressions rather than on crests. This could be explained by the 621 fact that crests are too exposed to the swell and tidal currents and therefore KF 622 would be overly subjected to high drag forces. These forces are lower in depressions 623 where KF are more sheltered. This explanation must be advanced with caution, 624 because the expected result involving the topography was a greater occurrence of 625 KF on crests rather than depressions (S. Derrien, com.pers.). Indeed, global 626 topography as used in this study is not efficient enough to predict KF variability 
627 correctly in shallow water which leads to limited prediction between LAT and $\mathrm{H}_{1}$. The

$628 \mathrm{BPI}$ computed on a finer scale than the one used here at a $150 \mathrm{~m}$ resolution, was 629 expected to be a more reliable variable to explain KF distribution at shallower depths.

630 The availability of proper high resolution depth data over the entire extent of the 631 coast of Brittany remains a major issue. This leads us to data quality issues.

632

633 Data quality - limitations and scale problem

634 The digital echo sounding system successfully characterised KF in the surveyed 635 areas and again demonstrated its ability to characterise and map aquatic vegetation, 636 as shown and validated in previous studies (McRea et al. 1999; Piazzi et al. 2000;

637 Brown et al. 2002; Freitas et al. 2003; Riegl et al. 2005; Freitas et al. 2006).

638 Nevertheless, the acoustic detection showed some limitations. The first one is the 639 binary classification of substratum: rock or not. Since the survey was conducted with

640 quite a small vessel, the results are sensitive to weather conditions and it is

641 recommended that surveys be conducted under calm weather conditions (without

642 swell and wind). Typical problems include: false KF detection, inaccuracy in the

643 evaluation of the instantaneous depth and number of Bottom Errors increasing with

644 wave height, leading to a degraded acoustic dataset. Research is still under way and

645 better results are expected with the improvement of the clustering algorithm,

646 particularly on some critical points:

647 - A decrease in the number of Bottom Errors. This would reduce the number of 648 misdetection of KF, especially on rocky substrata.

649 - A better submerged aquatic vegetation classification. For this study, transects were mainly assessed in pure KF areas, but in some locations (particularly in very shallow waters), different submerged aquatic vegetation species could be 
present (Zostera marina on the AW site, for example) and influence the classifying procedure. Better knowledge of the different species spectral signatures and taking them into account in the algorithm would reduce KF false detection.

656

657 Another type of input data required with the highest possible quality is the substratum 658 layer. KF are predicted only where a rocky substrate is present, by way of a mask of 659 the rocky area. At the working scale, i.e., pixels of $150 \mathrm{~m}$ covering the entire coast of 660 Brittany, these prediction errors are without consequences, since the obtained map 661 provides the prediction of the distribution and the inter-site variation of KF 662 frequencies at a global scale. However, if this model was adapted to finer scales in 663 order to predict local distributions and intra-site variations of KF, the current scale of 664 the substratum layer (not better than 1:500,000) would not be efficient and would 665 have to be refined. High resolution Lidar data, for example, could overcome this 666 limitation at a local scale. The ability of Lidar data to finely characterise seabed 667 substratum types was tested in recent studies (Rosso et al. 2006; Méléder et al. 2007). 668 Its high vertical and horizontal accuracy make it suitable to map bottom roughness and 669 topography in great detail (although at a high cost!).

670 Obviously, a good balance should be sought in scale homogeneity between source 671 data. For example, distribution laws as a function of depth used for model calibration 672 and validation were established using field bathymetry data from echo soundings, 673 whereas the model input raster dataset used for prediction was generated from 674 various sources at various resolutions (a mix of Lidar, digital soundings and map 675 soundings). Depth values from these two sources (map vs. field) exhibit 676 discrepancies leading to misprediction. For example, KF could be predicted on the 
677 map for an area where field depths were too great to be photosynthetically efficient or

678 conversely, some map areas where no KF were predicted corresponded to small

679 field depths allowing KF growth.

680 At the end of day, satellite data from SeaWiFS and AVHRR used are in accordance

681 with the current working scale for prediction at regional scale. However, similarly to

682 the substratum and bathymetry issues, image resolution limits the use of the model

683 for prediction at a local scale. MERIS, an ocean colour sensor aboard the Envisat 684 satellite, with a pixel resolution of $300 \mathrm{~m}$, will also allow progress towards finer 685 scales.

686 While progress is expected from regional to local levels, additional parameters may 687 have to be introduced in the model, as they may have an effect on KF at local scale, 688 and this would require new investigations. For example, the effect of faunal 689 abundance consuming primary producers or the swell effect through drag forces 690 and/or abrasion of rocky area by sand, fine topography, must be tested.

692 CONCLUSION

693 The proposed model enabled the prediction of KF frequency over time and space as 694 a function of water transparency and exposure, at a global scale that is effective in 695 the context of Climate Change. Its main limits were: a) predictions in shallow water 696 where the bathymetry at the working scale was not fine enough and b) the mostly 697 coarse scale of source data which did not allow local effects to be assessed. These 698 two limits could be overcome with an adaptation of the model, including refinement of 699 the working source data and the addition of new key parameters influencing 700 communities at local scales. Nevertheless, the current model is a good decisional 701 tool at a global scale, as in the context of Climate Change, allowing us to predict 
702 changes in the KF depth limit which could be used as an indicator of the health of 703 these communities and those associated with them.

704

705

706

707

708

709 
711 Bajjouk T, Guillaumont B, Populus J (1996) Application of airborne imaging

712

713

714

715

716

717

718

719

720

721

722

723

724

725

726

727

728

729

730

731

732

733

734

735

736

737

738

739

740

741

742

743

744

745

746

747

748

749

750

751

752

753

754

755

756

757 spectrometry system data to intertidal seaweed classification and mapping. HYDROBIOLOGIA 327: 463-471

Belsher T (1986) Etude bibliographique de quelques espèces planctoniques et benthiques de la Manche. Vol. 4 : Phytobenthos. Ifremer, Brest

Boller ML, Carrington E (2006) The hydrodynamic effects of shape and size change during reconfiguration of a flexible macroalga. J EXP BIOL 209: 1894-1903

Brinkman AG, Dankers N, van Stralen M (2002) An analysis of mussel bed habitats in the Dutch Wadden Sea. HELGOLAND MAR RES 56: 59-75

Brown CJ, Cooper KM, Meadows WJ, Limpenny DS, Rees HL (2002) Small-scale mapping of sea-bed assemblages in the eastern English Channel using sidescan sonar and remote sampling techniques. ESTUAR COAST SHELF S 54: 263-278

Buck BH, Buchholz CM (2005) Response of offshore cultivated Laminaria saccharina to hydrodynamic forcing in the North Sea. AQUACULTURE 250: 674-691

Cardoso PG, Raffaelli D, Lillebø AI, Verdelhos T, Pardal MA (2008) The impact of extreme flodding events and anthropogenic stressors on macrobenthic communities' dynamics. ESTUAR COAST SHELF S 76: 553-565

Combe JP, Launeau P, Carrere V, Despan D, Meleder V, Barille L, Sotin C (2005) Mapping microphytobenthos biomass by non-linear inversion of visibleinfrared hyperspectral images. REMOTE SENS ENVIRON 98: 371-387

Dayton PK, Tegner MJ, Parnell PE, Edwards PB (1992) Temporal and spatial patterns of disturbance and recovery in a kelp forest community. ECOL MONOGR 62: 421-445

de Jonge VN, de Jong DJ (2002) 'Global Change' impact of inter-annual variation in water discharge as a driving factor of dredging and spoil disposal in the river Rhine system and of turbidity in the Wadden sea. ESTUAR COAST SHELF S 55: 969-991

De Oliveira E, Populus J, Guillaumont B (2006) Predictive modelling of coastal habitats using remote sensing data and fuzzy logic. EARSeL eProceedings 5: 208-223

Denny M (1995) Predicting physical disturbance: mechanistic approaches to the study of survivorship on wave-swept shores. ECOL MONOGR 65: 371-418

Denny M, Gaylord B (2002) The mechanics of wave-swept algae. J EXP BIOL 205: 1355-1362

Ferrat L, Pergent-Martini C, Roméo M (2003) Assessment of the use of biomarkers in aquatic plants for the evaluation of environmental quality: application to seagrasses. AQUAT TOXICOL 65: 187-204

Freitas R, Rodrigues AM, Quintino V (2003) Benthic biotopes remote sensing using acoustics. J EXP MAR BIOL ECOL 285-286: 339-353

Freitas R, Sampaio L, J. O, Rodrigues AM, Quintino V (2006) Validation of soft bottom benthic habitats identified by single-beam acoustics. MAR POLLUT BULL 53: 72-79

Gaylord B, Denny M, Koehl MAR (2003) Modulation of wave forces on kelp canopies by alongshore currents. LIMNOL OCEANOGR 48: 860-871

Gohin F, Loyer S, Lunven M, Labry C, Froidefond J-M, Delmas D, Huret M, Herbland A (2005) Satellite-derived parameters for biological modelling in coastal 
waters: Illustration over the eastern continental shelf of the Bay of Biscay. REMOTE SENS ENVIRON 95: 29-46

Greve TM, Krause-Jensen D (2005) Predictive modelling of eelgrass (Zostera marina) depth limits. MAR BIOL 146: 849-858

Guillaumont B, Bajjouk T, Talec P (1997) Seaweed and remote sensing: a critical review of sensors and data processing. In: Round FE, Chapman DJ (eds) Progress in Phycological Research. Biopress, pp 213-282

Guillaumont B, Callens L, Dion P (1993) Spatial-Distribution and Quantification of Fucus Species and Ascophyllum-Nodosum Beds in Intertidal Zones Using Spot Imagery. HYDROBIOLOGIA 261: 297-305

Hurd CL (2000) Water motion, marine macroalgae, physiology, and production. J PHYCOL 36: 453-472

IPCC (2001) Climate change 2001: the scientific basis, contribution of working group I to the third assessment report of the Intergovernmental Panel on Climate Change (IPCC). Cambridge University Press, Cambridge

Kelly NM, Fonseca M, Whitfield P (2001) Predictive mapping for management and conservation of seagrass beds in North Carolina. AQUAT CONSERV 11: 437451

Koutsikopoulos C, Beillois P, Leroy C, Taillefer F (1998) Temporal trends ans spatial structures of the sea surface temperature in the Bay of Biscay. OCEANOL ACTA 21: 335-344

Lundblad ER, Wright DJ, Naar DF, Donahue BT, Miller J, Larkin EM, Rinehart R (2004) Classifying deep water benthic habitats around Tutulia, America Samoa 24th annual ESRI Conference, San Diego, CA

Marchalot C, Diner N, Berger L (2003) MOVIES+ documentation: Echo-integration by depth layers using MOVIES+ software. IFREMER/DNIS/ESI, Plouzané

Markager S, Sand-Jensen K (1992) Light requirements and depth zonation of marine macroalgae. MAR ECOL-PROG SER 88: 83-92

McRea JE, Greene HG, O'Connell VM, Wakefield WW (1999) Mapping marine habitats with high resolution sidescan sonar. OCEANOL ACTA 22: 679-686

MEDD (2005) Plan d'actions stratégique du MEDD pour les milieux marins. Tome 1 Diagnostic et Orientations. Ministère de l'écologie et du développement durable, Paris

Méléder V, Launeau P, Barillé L, Rincé Y (2003) Microphytobenthos assemblage mapping by spatial visible-infrared remote sensing in a shellfish ecosystem. $\mathrm{C}$ R BIOL 11: 437-451

Méléder V, Populus J, Rollet C (2007) Mapping seabed substrata using Lidar remote sensing. MESH - Mapping European Seabed Habitats. http://www.searchmesh.net/PDF/GMHM3 Mapping Substrata using LIDAR. pdf

Ménesguen A, Piriou JY, Dion P, Auby I (1997) Les "Marées vertes", un exemple d'eutrophisation à macroalgues. In: Dauvin J-C (ed) Les biocénoses marines et littorales françaises des côtes atlantiques, Manche et Mer du Nord. Synhtèse, menaces et perspectives. MNHN, Paris, pp 212-218

Norderhaug KM, Christie H, Rinde E (2002) Colonisation of kelp imitations by epiphyte and holdfast fauna; a study of mobility patterns. MAR BIOL 141: 965973

Piazzi L, Acunto S, Cinelli F (2000) Mapping of Posidonia oceanica beds around Elba Island (western Mediterranean) with integration of direct and indirect methods. OCEANOL ACTA 23: 339-346 
Pope ND, Widdows J, Brinsley MD (2006) Estimation of bed shear stress using the turbulent kinetic energy approach. A comparison of annular flume and field data. CONT SHELF RES 26: 959-970

Riegl BM, Moyer RP, Morris LJ, Virnstein RW, Purkis SJ (2005) Distribution and seasonal biomass of drift macroalgae in the Indian River Lagoon (Florida, USA) estimated with acoustic seafloor classification (QTCView, Echoplus). J EXP MAR BIOL ECOL 326: 89-104

Roff JC, Taylor ME (2000) National frameworks for marine conservation - A hierarchical geophysical approach. AQUAT CONSERV 10: 209-223

Rosso PH, Ustin SL, Hastings A (2006) Use of lidar changes associated with Spartina invasion in San Francisco Bay marshes. REMOTE SENS ENVIRON 100: 295-306

SHOM (1994-2005) Cartes sédimentologiques (G). SHOM

Sivertsen K (1997) Geographic and environmental factors affecting the distribution of kelp beds and barren grounds and changes in biota associated with kelp reduction at sites along the Norwegian coast. CAN J FISH AQUAT SCI 54: 2872-2887

Stevens T, Connolly RM (2004) Testing the utility of abiotic surrogates for marine habitat mapping at scales relevant to management. BIOL CONSERV 119: 351-362

Toms JD, Lesperance ML (2003) Piecewise regression: A tool for identifying ecological thresholds. ECOLOGY 84: 2034-2041

Vaslet D, Larsonneur C, Auffret J-P (1979) Carte des sédiments superficiels de la Manche. BRGM/CNEXO

Vogel S (1994) Life in Moving Fluids (2nd edn). Princeton University Press, Princeton, pp $467 \mathrm{pp}$.

Zacharias MA, Morris MC, Howes DE (1999) Large scale characterization of intertidal communities using a predictive model. J EXP MAR BIOL ECOL 239: 223-242

Zacharias MA, Roff JC (2001) Explanations of patterns of intertidal diversity at regional scales. J BIOGEOGR 28: 471-483 
Figure legend

842 Figure 1. Location of the 10 sites. Black star: sites used to build the model; white 843 star: sites used to validate it.

844

845 Figure 2. Echo-integration by depth layers in dense kelp forest (KF) on a selected 846 part of the acoustic transect. A: bottom line - Seafloor; B: offset line - down limit of 847 the Kelp forest integrated layer (0.2 meters above bottom); C: Top limit of the 848 integrated layer (2.2 meters above bottom). The vertical lines delimit each ESU (20 849 ping width).

850

851 Figure 3. Kelp forest frequency vs. depth. Example from the site Molène, Mo (cf.

852 Figure 1). Observations (O) are obtained from echo-sounding and are fitted using 853 piecewise regression (bold line), fixing the two breakpoints, $\mathrm{H}_{1}$ and $\mathrm{H}_{2}$, and the slope 854 between these points, Slope 2 . Fit is expressed with its prediction (fine line) and 855 confidence (dashed line) intervals at $95 \%$.

856

857 Figure 4. Weekly water transparency, expressed in $\mathrm{K}_{\mathrm{PAR}}$, derived from SeaWiFS data 858 averaged over the 1998-2004 period. a/ Sites used for model building; b/ Sites used 859 for model validation.

860

861 Figure 5. Weekly temperature, expressed in SST, derived from AVHRR data 862 averaged over the two past decades. a/ Sites used for model building; b/ Sites used 863 for model validation. 
865 Figure 6. Example of an echogram along a selected acoustic transect (from Gl site,

866 cf. Figure 1). The results of the cluster analysis classification procedure of KF 867 presence (LAMINAIRE) or absence (empty box) are presented in table above 868 echogram with the corresponding bathymetry $(\mathrm{m})$. For BOTT-ERR definition, see 869 Materials and Methods section.

870

871 Figure 7. KF frequency observed vs. predicted with the four significant models for 872 depth ranging from $\mathrm{H}_{1}$ to $\mathrm{H}_{2}$ at the five sites used to build model: AW, Mo, Me, $\mathrm{Tr}$ 873 and Gr. a/ pred_mod1: model using SSTmin only (eqs. 11 to 13 ), b/ pred_mod2: 874 model using $\mathrm{K}_{\text {PAR }} \min$ (eqs. 14 to 16), c/ pred_mod3: model using $\mathrm{K}_{\text {PAR }}$ min and

$875 V_{m a x}{ }^{1.5}$ (eqs. 14, 16 and 17), d/ pred_mod4: model using SSTmin and Vmax ${ }^{1.5}$ (eqs. 87611,13 and 18). Dark lines illustrate the relationship observation = prediction.

878 Figure 8. KF frequency observed vs. predicted using BPI (eq. 9), for depth less than $879 \mathrm{H}_{1}$ at the five sites used to build model: AW, Mo, Me, Tr and Gr. Dark lines illustrate 880 the relationship observation $=$ prediction .

882 Figure 9. Model validation. KF frequency observed vs. predicted at the five sites 883 used to valid model: $\mathrm{Au}, \mathrm{Br}, \mathrm{Gl}, \mathrm{He}, \mathrm{Ml}$. a/ prediction for depth ranging from $\mathrm{H}_{1}$ to $\mathrm{H}_{2}$ 884 using $\mathrm{K}_{\mathrm{PAR}} \min$ and $\mathrm{Vmax}^{1.5}$ (pred_mod3; eqs. 14, 16 and 17), or SSTmin and $885 \operatorname{Vmax}{ }^{1.5}$ (pred_mod4; eqs. 11,13 and 18 ) when no turbidity data are available; b/ 886 prediction for depth less than $\mathrm{H}_{1}$ using BPI (eq. 19). 
888 Figure 10. Predictive map of KF presence percentage. Three zooms are shown to 889 illustrate results: $\mathrm{AW}, \mathrm{Br}$ and $\mathrm{Gl}$, respectively in black, red and blue boxes.

890

891

892

893

894

895

896 


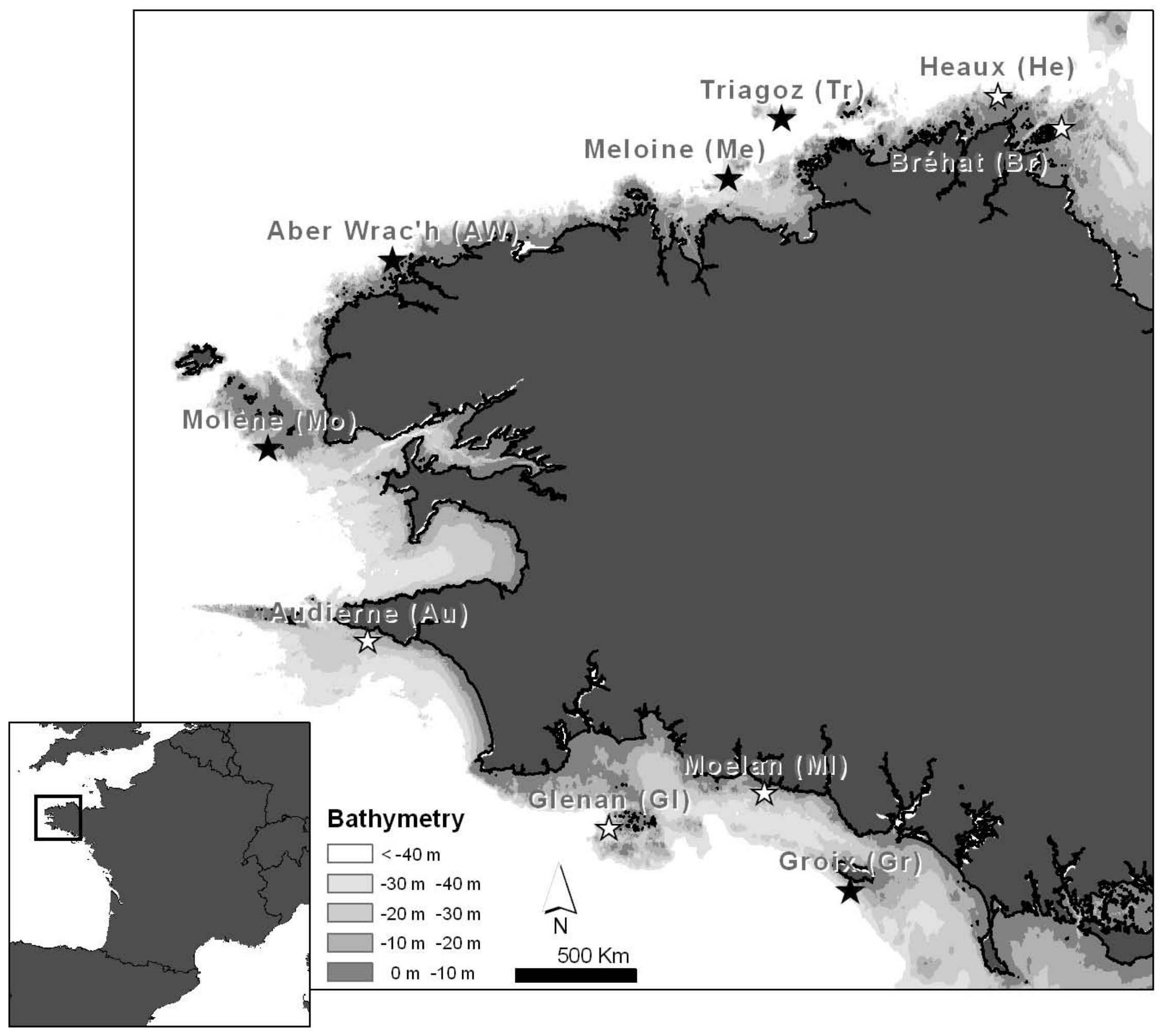




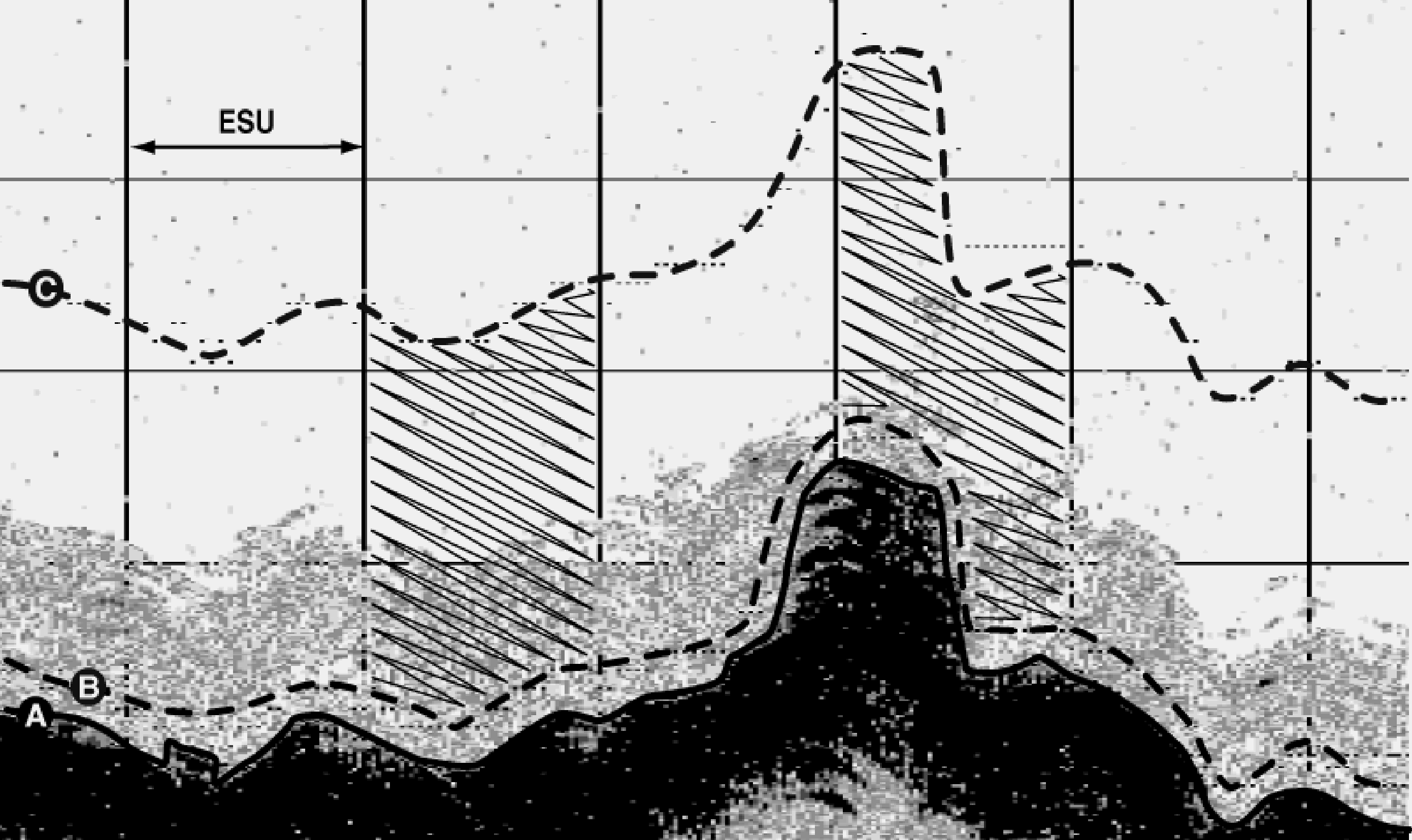

\section{$4+2 n$}

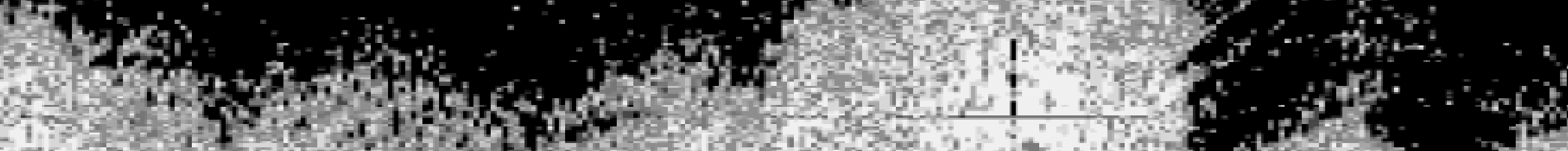

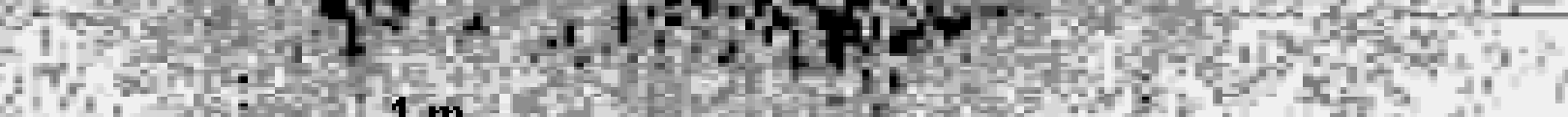
nin $+\mathrm{s} p \mathrm{~s}$

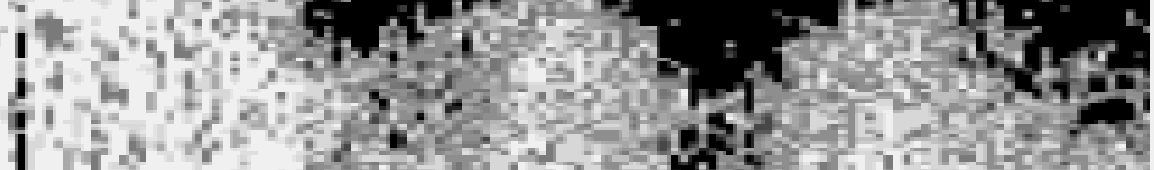




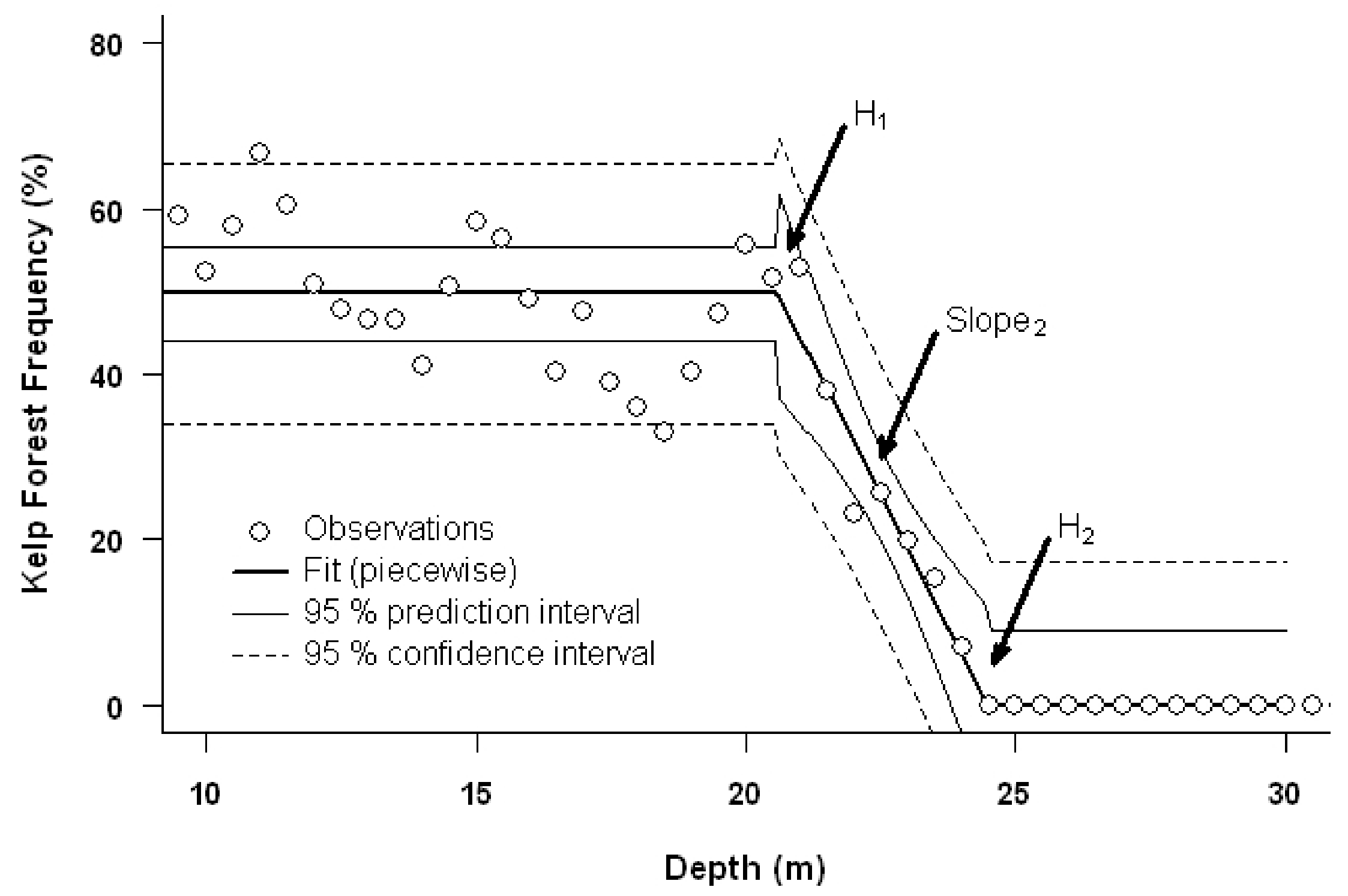



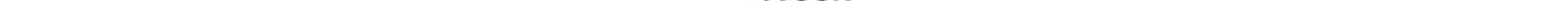


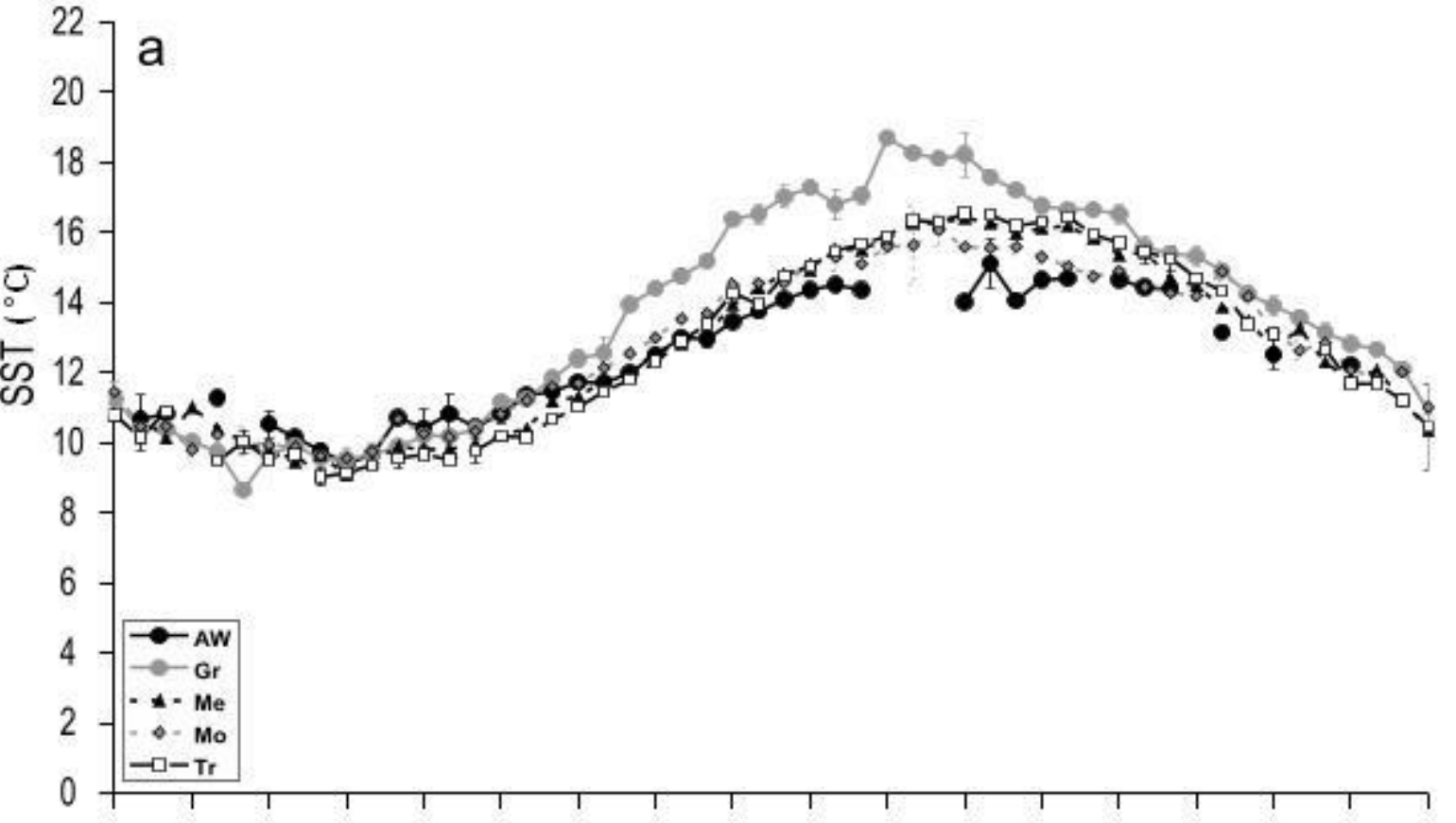




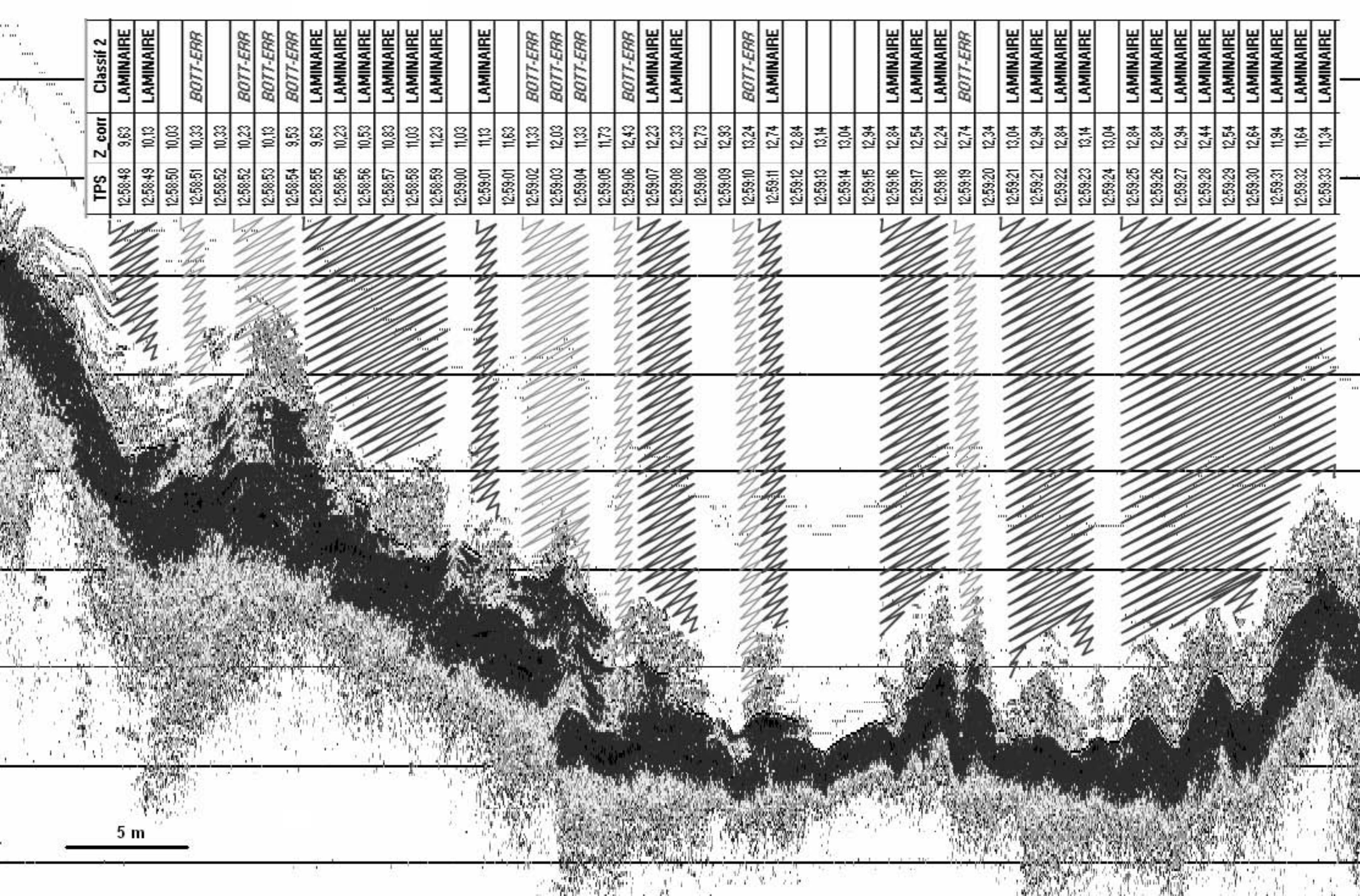




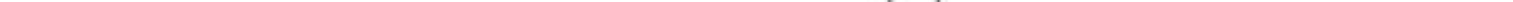




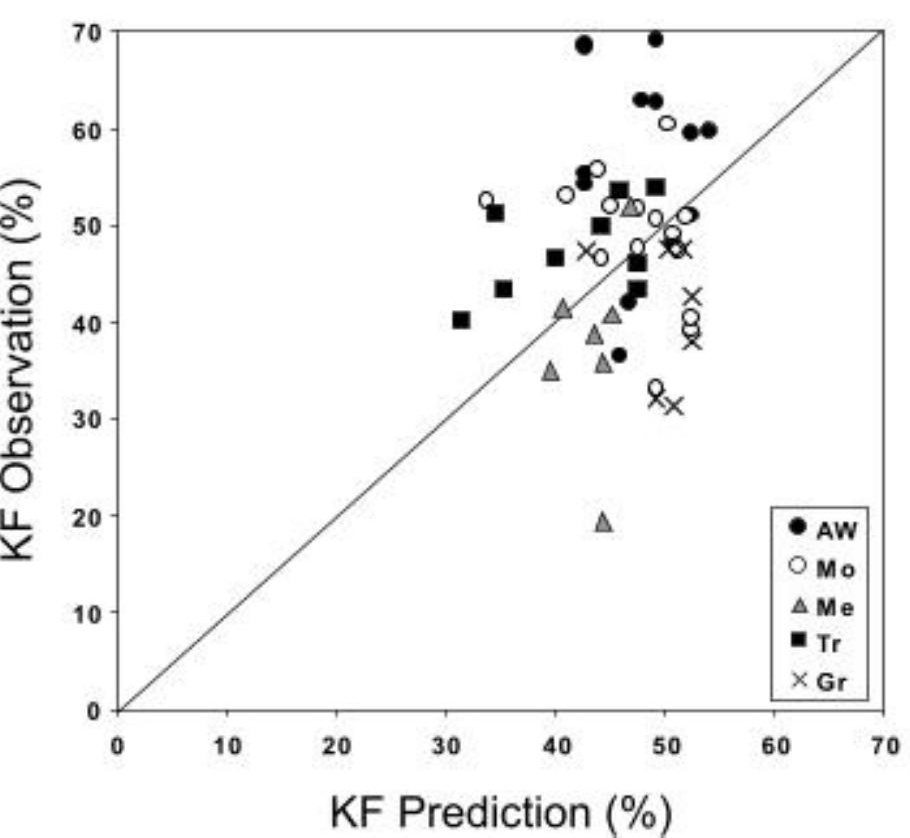


KF presence percentage $\mathrm{D}$ rock without $\mathrm{KF}$ 0 - 10 $10-20$ $20-30$ $30-40$ $40-50$ $50-60$ $60-70$ $70-80$ $80-90$ $90-100$ isoheight

- $0 \mathrm{~m}$

$-10 \mathrm{~m}$

$-20 \mathrm{~m}$

Substratum nature rocky area
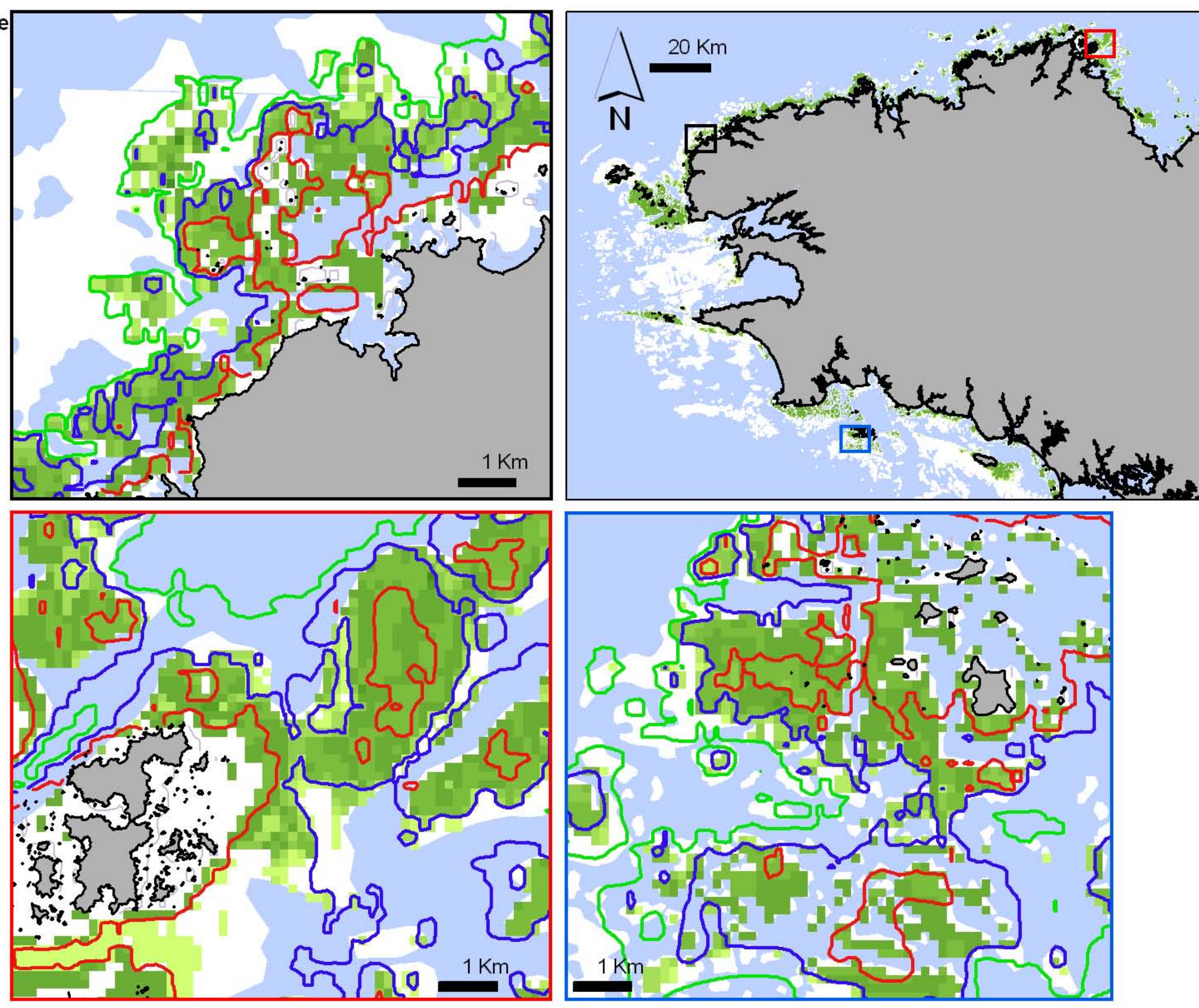

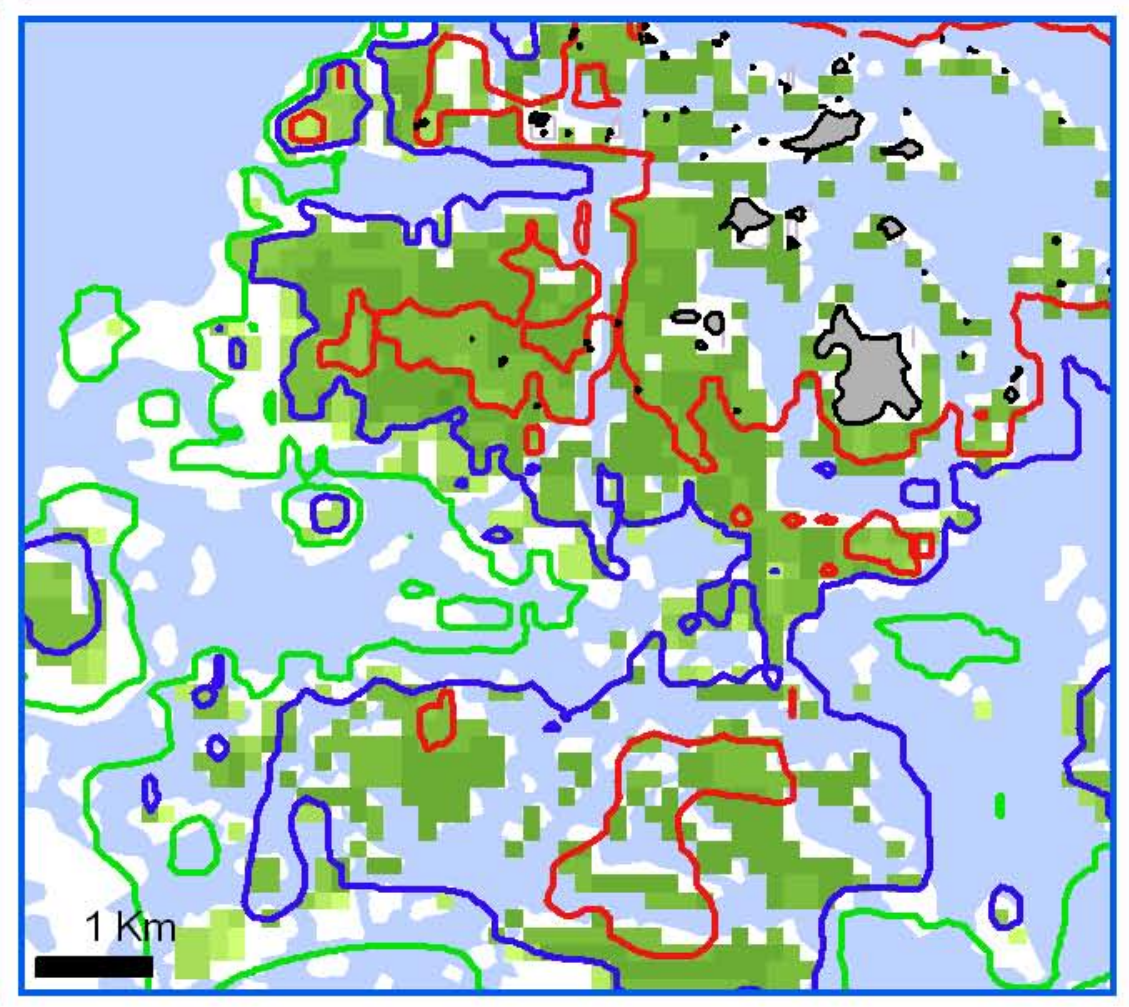


Table 1. Environmental parameters used in stepwise regression processes. Training sites are underlined, the others are validation sites.

\begin{tabular}{l|lllllllll}
\hline & K & & & & \\
$\underline{\mathrm{AW}}$ & 0.201 & 0.190 & 0.175 & 0.261 & 12.4 & 11.9 & 9.4 & 15.1 & 1.12 \\
$\underline{\mathrm{Gr}}$ & 0.265 & 0.194 & 0.202 & 0.456 & 13.6 & 12.9 & 8.7 & 18.7 & 0.27 \\
$\underline{\mathrm{Me}}$ & 0.215 & 0.191 & 0.183 & 0.268 & 12.7 & 11.6 & 9.1 & 16.4 & 0.89 \\
$\underline{\mathrm{Mo}}$ & 0.197 & 0.173 & 0.160 & 0.274 & 12.8 & 12.1 & 9.6 & 16.1 & 0.27 \\
$\underline{\mathrm{Tr}}$ & 0.202 & 0.176 & 0.176 & 0.281 & 12.7 & 11.5 & 9.0 & 16.5 & 0.95 \\
\hline $\mathrm{Au}$ & 0.205 & 0.171 & 0.164 & 0.321 & 13.1 & 12.7 & 8.9 & 18.5 & 0.44 \\
$\mathrm{Br}$ & 0.220 & 0.205 & 0.189 & 0.283 & 13.0 & 11.7 & 8.3 & 18.2 & 0.87 \\
$\mathrm{Gl}$ & 0.218 & 0.182 & 0.164 & 0.297 & 13.5 & 12.8 & 9.3 & 18.3 & 0.27 \\
$\mathrm{He}$ & 0.222 & 0.197 & 0.182 & 0.337 & 13.0 & 11.6 & 8.6 & 18.0 & 0.87 \\
$\mathrm{Ml}$ & - & - & - & - & 13.7 & 12.9 & 9.1 & 20.2 & 0.1 \\
\hline
\end{tabular}


Table 2. Breakpoints $\mathrm{H}_{1}$ and $\mathrm{H}_{2}$ and the slope between them, Slope 2 , fitted using piecewise regressions. All regressions and fit parameters are significant $(p \leq 0.01)$ except for sites $\mathrm{Au}, \mathrm{He}$ and Ml (n.s: not significant). Training sites are underlined, the others are validation sites.

\begin{tabular}{|c|c|c|c|c|c|c|c|c|c|c|}
\hline & $\underline{\mathrm{AW}}$ & $\underline{\mathrm{Gr}}$ & $\underline{\mathrm{Me}}$ & Mo & $\underline{\mathrm{Tr}}$ & $\mathrm{Au}$ & $\mathrm{Br}$ & $\overline{\mathrm{Gl}}$ & $\mathrm{He}$ & $\mathrm{Ml}$ \\
\hline adjusted $\mathrm{R}^{2}$ & 0.92 & 0.96 & 0.88 & 0.90 & 0.96 & 0.80 & 0.92 & 0.98 & 0.98 & 0.97 \\
\hline $\mathrm{H}_{1} \pm \mathrm{std}$ & $19.9 \pm 0.4$ & $15.5 \pm 0.4$ & $19.3 \pm 0.6$ & $20.6 \pm 0.5$ & $18.8 \pm 0.4$ & n.s. & $13.2 \pm 0.6$ & $15.2 \pm 0.3$ & $15.5 \pm 0.1$ & n.s. \\
\hline Slope $_{2} \pm$ std & $-11.5 \pm 1.5$ & $-8.9 \pm 0.8$ & $-8.8 \pm 0.9$ & $-12.5 \pm 0.8$ & $-9.3 \pm 1.1$ & $-3.6 \pm 0.4$ & $-4.9 \pm 0.4$ & $-6.0 \pm 0.2$ & n.s. & n.s. \\
\hline $\mathrm{H}_{2} \pm \mathrm{std}$ & $25.2 \pm 0.5$ & $19.6 \pm 0.4$ & $23.4 \pm 0.6$ & $24.5 \pm 0.6$ & $23.8 \pm 0.4$ & $22.3 \pm 1.6$ & $21.7 \pm 0.8$ & $25.8 \pm 0.4$ & $27.8 \pm 1.4$ & $22.3 \pm 0.8$ \\
\hline
\end{tabular}


Table 3. Fraction of incident light (in \%), Fr, reaching KF depth limit $\mathrm{H}_{2}$. $\mathrm{Fr}$ values are calculated (eq. 1) for four water transparency variables: $\mathrm{K}_{\mathrm{PAR}}$ year, $\mathrm{K}_{\mathrm{PAR}}$ growth, $\mathrm{K}_{\mathrm{PAR}} \min$ and $\mathrm{K}_{\mathrm{PAR}} \max$. Fr is not estimated for the site $\mathrm{Ml}$, because no turbidity data are available. Training sites are underlined, the others are validation sites.

\begin{tabular}{l|llll}
\hline & $F r_{H_{2}}$ (KPARyear) & $F r_{H_{2}}$ (KPARgrowth) & $F r_{H_{2}}$ (KPARmin) & $F r_{H_{2}}$ (KPARmax) \\
\hline$\underline{\mathrm{AW}}$ & 0.66 & 0.80 & 1.26 & 0.15 \\
$\underline{\mathrm{Gr}}$ & 0.57 & 2.32 & 1.95 & 0.62 \\
$\underline{\mathrm{Me}}$ & 0.64 & 1.17 & 1.36 & 0.18 \\
$\underline{\mathrm{Mo}}$ & 0.80 & 1.41 & 1.98 & 0.12 \\
$\underline{\mathrm{Tr}}$ & 0.78 & 1.51 & 1.46 & 0.12 \\
\hline $\mathrm{Au}$ & 1.04 & 2.19 & 2.56 & 0.08 \\
$\mathrm{Br}$ & 0.84 & 1.17 & 1.65 & 0.21 \\
$\mathrm{Gl}$ & 0.36 & 0.91 & 1.44 & 0.05 \\
$\mathrm{He}$ & 0.21 & 0.42 & 0.63 & 0.01 \\
$\mathrm{Ml}$ & - & - & - & - \\
\hline
\end{tabular}


Table 4. Prediction of KF depth limit $\mathrm{H}_{2}$. Observed $\mathrm{H}_{2}$ are from piecewise regression (Table 2), predicted and simulated $\mathrm{H}_{2}$ are from predictive model (pred_mod3 or pred_mod4*) but simulated ones follow varied scenarios (see text for detail). Training sites are underlined, the others are validation sites.

\begin{tabular}{l|llllc}
\hline Site & Observed $\mathrm{H}_{2}$ & Predicted $\mathrm{H}_{2}$ & Simulated $\mathrm{H}_{2(0.01)}$ & Simulated $\mathrm{H}_{2(0.02)}$ & Simulated $\mathrm{H}_{2(0.05)}$ \\
\hline$\underline{\mathrm{AW}}$ & $25.2 \pm 0.5$ & $25.0 \pm 0.6$ & $23.8 \pm 0.6$ & $22.4 \pm 0.6$ & $19.0 \pm 0.6$ \\
$\underline{\mathrm{Gr}}$ & $19.6 \pm 0.4$ & $20.2 \pm 0.0$ & $21.2 \pm 0.4$ & $22.8 \pm 0.4$ & $25.5 \pm 0.4$ \\
$\underline{\mathrm{Me}}$ & $23.4 \pm 0.6$ & $23.3 \pm 0.4$ & $22.1 \pm 0.4$ & $20.8 \pm 0.4$ & $17.2 \pm 0.4$ \\
$\underline{\mathrm{Mo}}$ & $24.5 \pm 0.6$ & $24.3 \pm 0.5$ & $23.3 \pm 0.5$ & $22.0 \pm 0.5$ & $18.4 \pm 0.5$ \\
$\underline{\mathrm{Tr}}$ & $23.8 \pm 0.4$ & $24.3 \pm 0.8$ & $23.1 \pm 0.8$ & $21.9 \pm 0.8$ & $18.2 \pm 0.8$ \\
$\mathrm{Au}$ & $22.3 \pm 1.6$ & $20.3 \pm 0.1$ & $21.4 \pm 0.1$ & $23.0 \pm 0.1$ & $25.7 \pm 0.1$ \\
$\mathrm{Br}$ & $21.7 \pm 0.8$ & $22.5 \pm 0.5$ & $21.26 \pm 0.5$ & $20.0 \pm 0.5$ & $16.4 \pm 0.5$ \\
$\mathrm{Gl}$ & $25.8 \pm 0.4$ & $24.0 \pm 0.1$ & $22.8 \pm 0.1$ & $21.6 \pm 0.1$ & $17.9 \pm 0.1$ \\
$\mathrm{He}$ & $27.8 \pm 1.4$ & $23.3 \pm 1.6$ & $22.1 \pm 1.6$ & $20.9 \pm 1.6$ & $17.3 \pm 1.6$ \\
$\mathrm{MI}$ & $22.3 \pm 0.8$ & $21.8 \pm 0.0$ & $23.0 \pm 0.0$ & $24.6 \pm 0.0$ & $27.2 \pm 0.0$ \\
\hline
\end{tabular}

